\title{
MAESTRO GERMÁN ARCINIEGAS EL EDUCADOR, ENSAYISTA, CULTURÓLOGO E IDEÓLOGO DE LOS MOVIMIENTOS ESTUDIANTILES EN COLOMBIA
}

\author{
Dr. Javier Ocampo López ${ }^{1}$ \\ Universidad Pedagógica y Tecnológica de Colombia- RUDECOLOMBLA. \\ Grupo de Investigación HISULA. SHELA \\ javierocampo11@yahoo.es
}

Recepción: 30/05/2008

Evaluación 01/06-15/09/2008

Aceptación: 29/09/2008

Artículo de Reflexión

\section{RESUMEN}

Este trabajo de investigación es un estudio sobre el pensamiento y la acción educativa del Maestro Dr. Germán Arciniegas, el Fundador de la Federación de Estudiantes de Colombia, quien inició el movimiento estudiantil en la Década de los Veinte del siglo XX. Se destaca su actividad como estudiante, diplomático, político, Ministro de Educación, educador universitario, periodista y académico de la Lengua y de Historia. Se estudian las ideas de este gran ensayista, autor de numerosas obras y artículos sobre la identidad de América Latina y sus relaciones con el mundo.

Se destaca su pasión por la educación con la fuerza de la creatividad para los latinoamericanos, como único camino para asegurar el futuro de estos pueblos del NUEVO MUNDO que durante cinco centurias han desarrollado una cultura propia, pero que necesitan el dinamismo de la integración y la unidad como lo defendieron los Libertadores.

\footnotetext{
${ }^{1}$ Doctor en Historia. Actualmente es profesor del Doctorado en Ciencias de la Educación de la Universidad Pedagógica y Tecnológica de Colombia RUDECOLOMBIA, miembro del Grupo de investigacion HISULA y de la Academia Boyacense de Historia.
} 
Ante las fuerzas recurrentes que buscan la desintegración y los nacionalismos locales, el Maestro Arciniegas luchó por la unidad de América Latina. Con sus obras publicadas señaló al Mundo que "América es otra cosa", diferente a lo que han querido los dominantes. América es la tierra de la libertad, la democracia y la república, que siempre ha vivido en constante lucha contra los imperialismos y las tiranías de los dictadores y los caudillos. El único camino es la educación de las nuevas generaciones, pensando siempre en la creación de una conciencia americana de identidad y de superación hacia el progreso y el desarrollo.

Palabras Claves: América Latina, identidad, autenticidad, integración e independencia. Americanidad. Americanismo en la libertad. Educación para la unidad y el progreso. Reforma Universitaria. Estudiante de la Mesa Redonda. Grito de Córdoba. Aporte de los estudiantes a la cultura. Movimientos estudiantiles. Europa en América, América en Europa. Descubrimiento de América. Comuneros, Independencia política, independencia mental, emancipación económica.

\title{
PROFESSOR GERMÁN ARCINIEGAS Educator, essayist, culture researcher and ideologist of the student movements in Colombia
}

\author{
Dr. Javier Ocampo López \\ Universidad Pedagógica y Tecnológica de Colombia-RUDECOLOMBIA. \\ Grupo de Investigación HISULA - SHELA \\ javierocampo11@yahoo.es
}

\begin{abstract}
This research work is a study of Professor Germán Arciniegas and his thought, Founder of the Federation of Students of Colombia, who began the student movement in the 20s decade in the XX century. It stands out his activity as a student, diplomat, political, Secretary of Education, university professor, journalist and academic of Languages and History. He's an essayist of great ideas, author of numerous works and articles that study the identity of Latin America and its relationship with the world.
\end{abstract}


Key Words: Latin America, identity, authenticity, integration, independence, Americanhood

\section{INTRODUCCIÓN}

En el suceder de las Generaciones existen grandes pensadores cuyas ideasfuerza-acción se convierten en directrices espirituales de los pueblos y, en voceros de su concepción del mundo y de la vida; de su ontología o razón de ser; de su sistema de ideas y de sus aportes significativos a la cultura universal. Uno de ellos, fue el escritor Maestro Germán Arciniegas. (1900-1999), el colombiano universal, el educador, el ensayista e historiador, el humanista, quien más escribió con convicción y pasión sobre la americanidad, el mundo universitario y los movimientos estudiantiles, de los cuales fue el dirigente iniciador en Colombia en la década de los Veinte del siglo XX. Arciniegas fue el auscultador de las fuerzas históricas de América en sus estructuras filosóficas; el escritor que más recalcó sobre las dimensiones profundas y luminosas de la americanidad, la dinámica en el proceso histórico-cultural de este Pueblo de América, un continente de siete colores como él lo llamó en su Historia de la Cultura. Según el Maestro, Latinoamérica es la tierra de la democracia, aunque siempre ha vivido entre la libertad y el miedo. Por ello fue considerado como el abanderado de la idea del americanismo en la libertad, como filosofía profunda del Nuevo Mundo.

Este trabajo de investigación tiene por objeto el estudio de las ideas del Maestro Germán Arciniegas a través de sus obras y numerosos artículos publicados en revistas humanistas, tanto en Colombia, como en Latinoamérica y el Mundo. Para su desarrollo se utilizó el método de la Historia de las Ideas y del Pensamiento, cuyo objetivo es el estudio de las ideas de las gentes y en especial de grandes pensadores e ideólogos. El análisis de los actos de entendimiento y conocimiento de las cosas; y las reflexiones sobre los fenómenos espirituales, materiales, naturales, y sobre el humanismo universal. Se interesa por todo testimonio de las actividades y lo que piensan las personas, que es producto de la mente humana.

Al investigar las ideas de un pensador en el tiempo y en el espacio se buscan las esencias históricas, lo cual significa que para esta investigación sobre el pensamiento del Maestro Germán Arciniegas, tenemos en cuenta que sus ideas, reflejadas en sus numerosas obras y artículos, no se estudiaron en forma abstracta, sino en función de la realidad que vivió en el siglo XX, o sea, las 
circunstancias que generaron sus ideas. Para su análisis o Hermenéutica se utilizó la doxografía temática y cronológica, a través de la semántica cuantitativa y cualitativa de las ideas, culminando con la etiología y síntesis de su pensamiento. ${ }^{2}$

\section{El Maestro Arciniegas y la Generación de los Nuevos}

El Maestro Germán Arciniegas nació en Bogotá el 6 de diciembre de 1900, en los umbrales del nuevo siglo; y murió en la misma ciudad, el 30 de noviembre de 1999. Por ello, en el año finisecular, al terminar el siglo, fue considerado como uno de los más grandes escritores colombianos del siglo XX en el panorama latinoamericano y mundial.

Las dos primeras décadas del siglo XX corresponden a los años del nacimiento de los colombianos llamados de la Generación de los Nuevos, o de la Postguerra, quienes tuvieron su mayor vigencia entre 1940 y 1960 . Ellos nacieron en unos años cuando Colombia despertaba a la modernización, después de la Guerra Civil de los Mil Días, la anarquía y la crisis económica. Las luchas entre conservadores y liberales dejaron al país en desolación, tragedia y crisis nacional; el debilitamiento de las instituciones políticas, los rencores políticos partidistas y la separación de Panamá. Les correspondió actuar en un siglo de crisis mundiales: La Primera, la Segunda Guerra Mundial y la Post-guerra; y a nivel nacional, una época de conmociones sociales, políticas y militares y de los llamados "Años de la Violencia" y del Frente Nacional.

Inicialmente los escritores de esta Generación se reunieron alrededor de dos revistas literarias: la revista de "Los Nuevos", dirigida en Bogotá por los escritores Alberto Lleras Camargo y Jorge Zalamea Borda; y la revista "Pánida" en Medellín, dirigida por el poeta León de Greiff. Los Nuevos y los Pánidas defendieron la modernización de Colombia y los cambios urgentes de nuestra sociedad. Ellos surgieron en una época de desequilibrio económico, agitación de masas y crisis de las ideologías decimonónicas. Fueron los años cuando los escritores y políticos auspiciaron el reformismo social, la secularización filosófica, el cientificismo y la tecnocracia; cuando se propiciaron estudios científicos y sociales para el análisis verdadero de los problemas nacionales, con métodos de tipo empírico y científico. Para los nuevos científicos sociales aparecieron

\footnotetext{
${ }^{2}$ Sobre una metodología de la Historia de las Ideas, véase la obra de VOVELLE, Michael. (1985): Ideologías y mentalidades. Barcelona, Editorial Ariel. LAURENCE, Bandin. (1996): El Análisis de Contenido, Madrid, Ediciones Akal. Asimismo, las obras del Maestro GAOS, José. (1967): De la Filosofía, México, Fondo de Cultura Económica, y su obra De Antropología e Historiografía. México, Universidad Veracruzana.
} 
nuevas fuentes de investigación a través de la entrevista, el campo, el barrio y los grupos sociales. Y a nivel de los pensadores ensayistas, como el Maestro Arciniegas, con escritos muy profundos sobre la americanidad y la posición y visión del Nuevo Mundo en la cultura universal.

Ante la problemática socio-económica, la lucha de los partidos políticos y el inconformismo nacional, los Nuevos defendieron la idea de la "modernización" de Colombia, la planificación para la búsqueda de un futuro con sólidos pilares y la tecnificación de acuerdo con los tiempos nuevos. Entre los colombianos más destacados de la Generación de los Nuevos, señalamos a los escritores, políticos

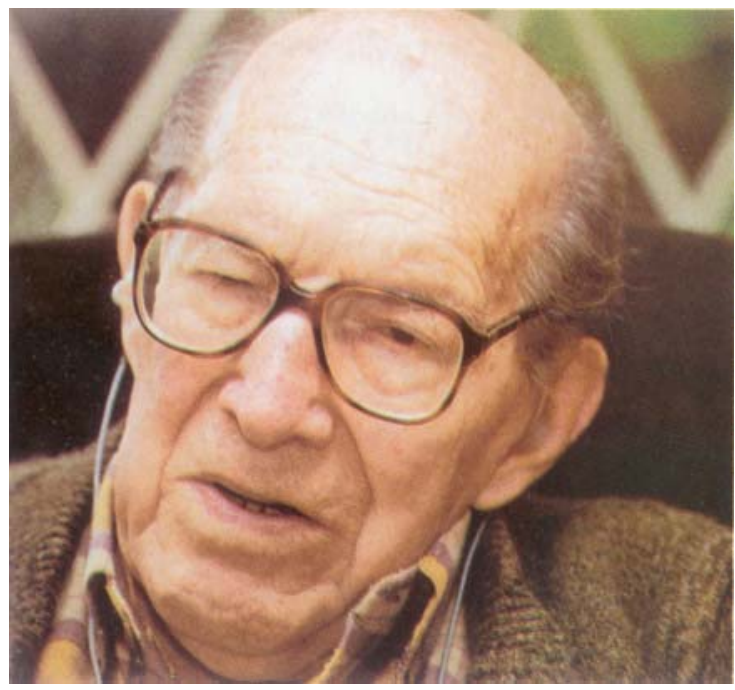
y estadistas: Germán Arciniegas, León de Greiff, Jorge Zalamea Borda, Germán Rafael Maya, Eduardo Caballero Calderón, Aurelio Arturo, Alberto Lleras Camargo, Carlos Lleras Restrepo, Darío Echandía, Juan Lozano y Lozano, Gabriel Turbay, Jorge Eliécer Gaitán, Antonio Álvarez Restrepo, Augusto Ramírez Moreno, Guillermo León Valencia, Gustavo Rojas Pinilla, Gilberto Alzate Avendaño, Silvio Villegas, Fernando Londoño y Londoño, Rafael Torres Quintero, Rafael Bernal Jiménez, Luis Ángel Arango, Germán Pardo García, Eduardo Zalamea Borda, Luis Gabriel Cano, Roberto García Peña, Luis Alberto Acuña, Edgar Negret y otros. ${ }^{3}$

Para los latinoamericanos, la entrada al siglo XX fue la irrupción de un mundo nuevo, lleno de esperanzas, como así se reflejó en la obra "Ariel" del pensador uruguayo José Enrique Rodó, que influyó en la juventud hispanoamericana. Fue la obra literaria que transmitió la filosofía del nuevo Humanismo a la juventud del Nuevo Mundo de Nuestra América Mestiza. Ariel es la juventud de este mundo hispanoamericano, nuevo en el transcurrir de las Generaciones. Un mundo espiritual que está inmerso en el humanismo y en el antropocentrismo de las libertades. Ariel es contrario a Calibán, el mundo de la tecnocracia y del pragmatismo. Es el enfrentamiento entre Ariel

\footnotetext{
${ }^{3}$ NARANJO VILLEGAS, Abel. (1965): Morfología de la Nación Colombiana (Aproximación a su Antropología Cultural). Bogotá, Academia Colombiana de Historia, Historia Extensa de Colombia, Tomo XXII. Ediciones Lerner.
} 


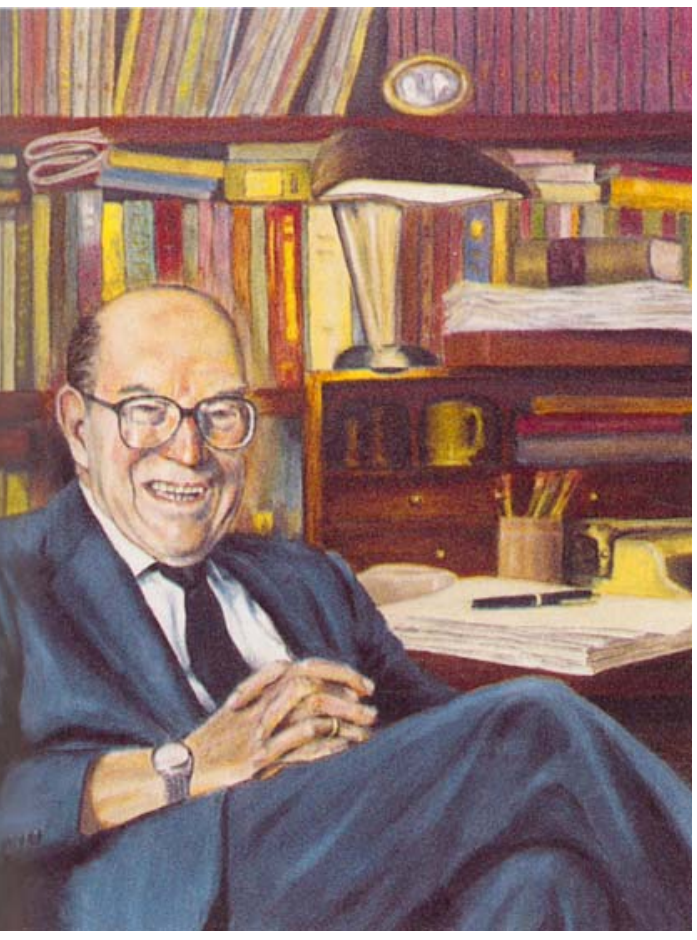

(Hispanoamérica) y Calibán (Estados Unidos), como grito de alerta a la juventud en los umbrales del siglo XX. ${ }^{4}$

Con el escritor Rodó se popularizaron también las bellas poesías modernistas del escritor nicaragüense Rubén Darío. Era la iniciación de la vida nueva de "Nuestra América", según las ideas del pensador cubano José Martí; un mundo de la integración y de la solidaridad latinoamericana. Los latinoamericanos de la iniciación del siglo XX, y en especial, la Generación de los Nuevos en Colombia, combatieron "la política del garrote" del presidente norteamericano Teodoro Roosevelt, quien para salvar sus intereses en el Canal, propició la Separación de Panamá en relación con Colombia. Como reacción a Estados Unidos, "Los Nuevos" propiciaron el antiimperialismo y lucharon por la unidad latinoamericana, por el amor a lo terrígeno y lo autóctono o propio, característico de la identidad nacional y provincial. ${ }^{5}$

\section{La familia del Maestro Arciniegas}

Sus padres fueron Don Rafael Arciniegas Tavera, originario del Tolima y doña Josefa Aurora Angueira Figueredo, de familia cubana. En las guerras civiles, la familia Arciniegas, de política liberal radical, perdió su fortuna en Natagaima, trasladándose a Bogotá. Su madre, doña Aurora Angueira Figueredo, natural de Tunja era de familia cubana, hija del ingeniero Basilio Angueira Perdomo y de María de la Luz Figueredo Vásquez, patriotas cubanos. Perucho Figueredo, su abuelo fue perseguido por el gobierno español en Cuba, por su liberación de los esclavos y por el asalto de Bayamo; era además músico y compositor, autor de "La Bayamesa", compuesto en 1867, el primer himno nacional cubano. Fue el canto patriótico para exigir la independencia de Cuba, contra los españoles. También elaboró la primera bandera cubana, que llevó su tía abuela Candelaria, que fue heroína de la independencia.

\footnotetext{
${ }^{4}$ RODÓ, José Enrique. (1957): Ariel, en Obras Completas de José Enrique Rodó Madrid, Editorial Aguilar.

${ }^{5}$ ARÉVALO, Juan José. (1956): Fábula del tiburón y las sardinas. América Latina estrangulada. México, Ediciones América Nueva.
} 
Su familia Angueyra Figueredo recibió persecuciones por la Libertad; por ello, el Maestro Arciniegas heredó el carácter independiente de luchador constante por la libertad y la democracia. Él siempre llevaba la Libertad como el argos de su utopía; la respiraba hasta por los poros todos los días. ${ }^{6}$

Como Colombia en los años del Radicalismo estaba en un auge de progreso y desarrollo de las vías de comunicación, estimuló la construcción de ferrocarriles. Por ello contrató ingenieros cubanos, uno de los cuales fue Francisco J. Cisneros para Antioquia y Francisco María de Angueira para el ferrocarril de la Sabana, quien trajo a su hijo Basilio Angueira, quien trabajó en el Estado de Boyacá a partir de 1876.

El ingeniero Basilio Angueira trabajó en Boyacá en el Camino de Occidente, entre Chiquinquirá y Puerto Niño, la construcción de puentes en el río Chicamocha en los pasos de León y Capitanjeo, el obelisco en el Puente de Boyacá, la Plaza de Bolívar en Tunja y otras obras. En la Casa de La Torre en Tunja nació Aurora Angueira Figueredo, quien se casó con Rafael Arciniegas Tavera, los padres del Maestro Germán Arciniegas, quien nació en Bogotá el 6 de diciembre del año 1900. Fue bautizado en la Iglesia de la Veracruz el 6 de febrero de 1901.

Sus primeras letras las hizo en el Colegio Pestalozziano de Bogotá, con su primera Maestra, la educadora María Gooding. Desde su niñez y juventud manifestó su afición por las letras, y en especial por la literatura, la historia y el periodismo. Hizo parte de los Boy Scauts, el primer grupo que se fundó en Colombia, con la instrucción de Daniel Samper Ortega. Sus estudios secundarios los hizo en la Escuela Nacional de Comercio, que regentaba el físico y astrónomo Guillermo Wickman. Entre sus profesores se destacaron Eduardo Posada, Ramón Zapata, José Joaquín Guerra y otros.

El 2 de febrero de 1918 ingresó a la Facultad de Derecho y Ciencias Políticas de la Universidad Nacional de Colombia. Era Rector de la institución el Dr. Antonio José Cadavid y Secretario el Dr. Clemente Martin Fernández; en 1919 fue Rector el doctor Antonio José Uribe. En 1919, el joven Arciniegas se vinculó al periódico "El Tiempo", que dirigía el Dr. Eduardo Santos; su primer artículo fue "O Educación O Exámenes".

${ }^{6}$ CACÚA PRADA, Antonio. (1990a): De Cuba a Boyacá por la Libertad. Dos Angueyras y Germán Arciniegas, Tunja, Academia Boyacense de Historia. 
En 1920, el estudiante Germán Arciniegas se interesó por la creación de la FEDERACIÓN DE ESTUDIANTES, con la colaboración del poeta mexicano Carlos Pellicer, quien era estudiante de la Preparatoria. En la política de Relaciones Exteriores de México, el Presidente José Vasconcelos se preocupó por enviar un estudiante como Agregado Cultural de México en cada Embajada. Por ello, Carlos Pellicer llegó a Bogotá y se puso en contacto con el joven Germán Arciniegas, Director del periódico "Voz de la Juventud". Se instaló la Asamblea de Estudiantes y se eligió la Junta Directiva. Al joven Arciniegas lo nombraron Secretario Perpetuo. Como dirigente estudiantil hizo diversas actividades para fortalecer la Federación de Estudiantes. Germán Arciniegas culminó sus estudios y fue graduado en Derecho y Ciencias Políticas de la Universidad Nacional. Sin embargo, su profesión de abogado no la regentó, pues su interés fueron los problemas humanísticos, educativos, diplomáticos y políticos; y en especial, todo lo relacionado con el hombre y su cultura. ${ }^{7}$

En la evolución de sus actividades estudiantiles, diplomáticas, políticas, estadistas y académicas, se pueden señalar varios ciclos en su vida: Un primer ciclo de 10 años entre 1916 y 1926, "ElEstudiante", que corresponde a su vida estudiantil, y en especial, su actividad como dirigente de la Federación de Estudiantes Universitarios. Un segundo ciclo de diez años, "ElDiplomático", que corresponde a su actividad diplomática en Latinoamérica y Europa, entre los años 1927 y 1937. Un tercer ciclo, "El Estadista”, entre los años 1938 y 1945, cuando ejerció el cargo de Ministro de Educación en los Gobiernos de los Presidentes Eduardo Santos y Alberto Lleras Camargo. Un cuarto ciclo de "El Americanista exiliado", entre los años 1946 y 1956, cuando se dedicó a sus actividades docentes en varias Universidades de los Estados Unidos y a su lucha a través de sus escritos, contra las Dictaduras de América Latina, en unos años entre la Libertad y el Miedo. Un quinto ciclo de "ElColombiano Universal", entre los años 1957 y 1980, con sus actividades intelectuales y docentes en el mundo universitario. Un sexto ciclo, "El Académico", entre los años 1980 hasta su muerte en 1999.

\section{Germán Arciniegas, el estudiante de la Mesa redonda}

Germán Arciniegas fue el eterno estudiante de América. En sus escritos y en sus acciones siempre llevó el alma y el ojo avisor del "Argos estudiantil". Así lo manifestó en su primera obra "El estudiante de la Mesa redonda", publicada en Madrid en la Editorial de Juan Pueyo 1932, (248 páginas), que tuvo fama a

\footnotetext{
${ }^{7}$ Ibídem, pp. 5-72
} 
nivel nacional e hispanoamericano. Es la vida del estudiante y su presencia histórica en el desenvolvimiento de los pueblos europeos y americanos desde la Edad Media hasta el siglo XX. No se entiende la Historia del Mundo Occidental, sin la presencia de los estudiantes, quienes con sus anhelos de cambio, siempre están analizando su realidad en prospectiva hacia el futuro. ${ }^{8}$

Según el Maestro Arciniegas, en la Historia de la Humanidad se destaca el papel de los estudiantes, quienes han hecho lo más trascendental en el desarrollo de las sociedades. Los estudiantes son la rebeldía, la inquietud, el repudio del pasado, el ansia de lo nuevo, la investigación, el asalto, el heroísmo. Ellos son los descubridores, los conquistadores, los sabios, los santos, los libertadores, los transformadores, los poetas. Según las ideas de Arciniegas, todo el progreso moral, mental y material de la especie

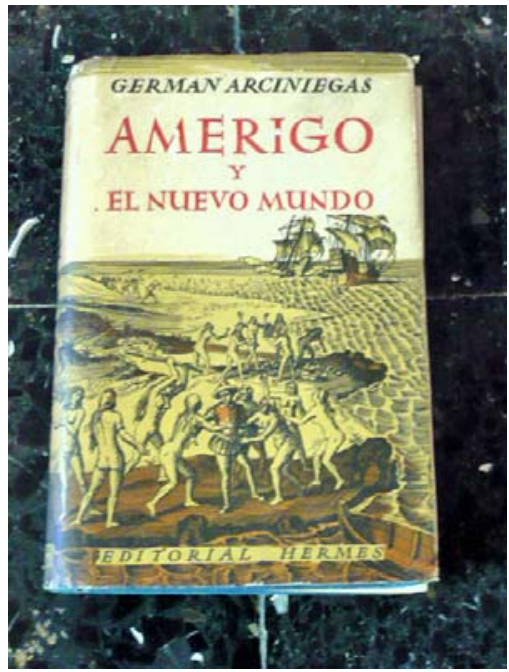
es obra de los estudiantes.

En esta primera obra del Maestro Arciniegas, se refleja su espíritu estudiantil, siempre alegre, pero siempre indómito. Por su obra pasan los estudiantes en el Descubrimiento de América, los aventureros de la conquista, los conquistadores, los libertadores de los nuevos Estados Nacionales, los políticos y todos los que piensan en los cambios urgentes de nuestra América. No se entiende la insurrección de Nuestra América para los cambios políticos, socio-económicos y educativos, sin la intervención directa de los estudiantes. Su lucha ha sido constante contra las injusticias, el oscurantismo y la censura; ellos siempre han dado la batalla por la modernidad y la ilustración. Según Arciniegas, "la Revolución de Independencia en América no es obra de caudillaje, ni idea surgida del cuartel, sino fórmula de campesinos puesta a limpio por estudiantes de vanguardia"."

En el siglo XIX el estudiante luchó por la libertad de conciencia, la libre cátedra, la libertad de expresión, la escuela laica, gratuita y obligatoria, la abolición de la pena de muerte y el repudio al militarismo. Así expresó sobre los estudiantes de todos los tiempos:

\section{... Somos los estudiantes de América. ... Y aqui estamos todos, muchachos} de la vieja Europa, muchachos que hace cuatro o seis siglos fueron el escándalo en

\footnotetext{
${ }^{8}$ CACÚA PRADA, Antonio. (1990b): Germán Arciniegas. Su vida contada por él mismo. Bogotá, Universidad Central, Instituto Colombiano de Estudios Latinoamericanos y del Caribe. Asímismo, la obra de COBO BORDA, Juan Gustavo. (1990): Germán Arciniegas. Cronologia y Bibliografía. Bogotá, Planeta Editores.

${ }^{9}$ ARCINIEGAS, Germán. (1982): El estudiante de la mesa redonda, Madrid, Juan Pueyo. Véase la nueva edición de Plaza \& Janés, Bogotá.
} 
París o Salamanca, y los de ahora, que fomentan disturbios en Madrid, en Córdoba, Lima. ${ }^{10}$

En la obra "El estudiante de la mesa redonda" aparecen los estudiantes frailes contra los caballeros de las cruzadas, los mareantes y los aventureros, los que conocieron y participaron en las polémicas de Salamanca y Córdoba; los seminaristas que se enfrentaron a los Inquisidores; los Sabios que como Caldas, hicieron las primeras investigaciones científicas y naturales; los obreros y trabajadores que participaron en los movimientos sociales de los siglos XVIII y XIX, los estudiantes que intervinieron en los prolegómenos revolucionarios, con pasquines y escritos satíricos, los estudiantes que sin terminar sus carreras profesionales se vincularon a los ejércitos patriotas y fueron decisivos en la culminación de la Independencia; y los estudiantes que impulsaron las Reformas de Córdoba en 1918 en Argentina, que tuvieron trascendencia en las reformas universitarias en América.

En todos sus escritos sobre los estudiantes y su influencia en la Historia americana, se manifestó el Maestro Arciniegas como "Un eterno estudiante de la mesa redonda"; el historiador que penetra profundamente en el suceder y en la vida cotidiana de las grandes multitudes americanas y en los círculos estudiantiles de las Universidades latinoamericanas. Fue su pasión constante, que se reflejó en sus libros y en sus artículos y que se proyectó en su pensamiento sobre la búsqueda de la identidad de Nuestra América, de sus grandes hechos y personajes de carne y hueso, y de multitudes y estudiantes, sin cuyas actuaciones históricas no es posible el conocimiento del alma latinoamericana.

\section{4. "El Grito de Córdoba” y la lucha estudiantil en Latinoamérica}

Cuando en el año 1918, el joven Arciniegas ingresó a la Facultad de Derecho y Ciencias Políticas de la Universidad Nacional de Colombia, se preocupó por los problemas estudiantiles y se fijó la meta de organizar para Colombia la Federación de Estudiantes. Fue el año cuando los estudiantes de la Universidad de Córdoba (Argentina) lucharon contra la estructura tradicional universitaria y anunciaron el despertar de una juventud anhelante de cambio y modernización. 
El Manifiesto de Córdoba, promulgado el 15 de julio de 1918, fue dirigido a la juventud argentina y a los hombres libres de Sudamérica. Se convirtió en una declaración de principios de la Reforma Universitaria: autonomía política, doctrinal, docente y administrativa de la Universidad; democratización de la Universidad con la participación de directivos, profesores y alumnos; elección de las autoridades universitarias por la asamblea conformada por los tres elementos constitutivos de la Universidad; selección de profesores por medios exclusivamente académicos; libertad de enseñanza; libertad de asistencia; instrucción gratuita: nuevos programas; nuevos métodos de enseñanza, asignaturas y objetivos de la educación. Integración de la educación universitaria en unidad con la elemental y secundaria. Relación íntima entre la Universidad y los problemas nacionales.

Los estudiantes de Córdoba lucharon contra la Universidad tradicional con estructuras coloniales y la cátedra magistral; defendieron el gobierno de estudiantes y profesores en el manejo de la Universidad; consideraron fundamental la cátedra por concurso, la autonomía universitaria, la democratización de la Universidad, la investigación científica, la extensión universitaria a la comunidad, la libertad de pensamiento y de cátedra, la ampliación y diversificación de las carreras universitarias; la asistencia social a los estudiantes y otros aspectos. ${ }^{11}$

E1 Grito de Córdoba hizo reflexionar a los universitarios latinoamericanos sobre la dependencia cultural de estos países en relación con Europa y Estados Unidos y la necesidad de buscar la autonomía y la esencia de la propia identidad. Asimismo, en luchar por la búsqueda de soluciones a los grandes problemas nacionales.

El ideario de Córdoba tuvo su impacto en Argentina y se convirtió en realidad a través de la Reforma Universitaria de Yrigoyen de octubre de 1918, la cual se difundió en Hispanoamérica, especialmente en Uruguay, Chile, Perú, Venezuela, Colombia, Cuba, México y otros países, convirtiéndose en la bandera de las nuevas generaciones hispanoamericanas para la modernización de la educación universitaria. La democratización de la educación, de acuerdo con

\footnotetext{
${ }^{11}$ Sobre el Grito de Córdoba de 1918, véase el estudio de VERA DE FLACHS, María Cristina, Reformas y contrarreformas en la Universidad de Córdoba 1918-1936. En la obra Movimientos Universitarios. América Latina Siglo XX. Editor: VARGAS, Olmedo. (2005): Tunja, Rudecolombia, pp. 117-140. Asímismo, la obra de RIBEIRO, Darcy. (1971): La Universidad Latinoamericana. Caracas, Universidad Central de Venezuela. Véase también la obra de OCAMPO LÓPEZ, Javier. (1987): Historia de la Cultura Hispanoamericana. Siglo XX. Bogotá, Plaza \& Janés.
} 
el "Grito de Córdoba” llevó a los sectores populares a las aulas universitarias, transformando en sus bases la estructura de la Universidad. ${ }^{12}$

\section{Germán Arciniegas el dirigente estudiantil}

El estudiante Germán Arciniegas con un grupo de compañeros se interesó en 1920 por organizar la FEDERACIÓN DE ESTUDIANTES, con el objetivo de luchar por la Reforma Universitaria y por defender la Libertad de Cátedra en un pueblo con gran influencia de la Iglesia Católica en la educación. En sus intervenciones ante los estudiantes, Arciniegas insistía sobre los cambios urgentes para Colombia; asimismo, en la Reforma Educativa y en la Reforma Universitaria. En el año 1921 fue la organización definitiva de la Federación de Estudiantes de Colombia, con la colaboración del escritor Carlos Pellicer, enviado de los estudiantes de México. En febrero de 1921 surgió la primera Federación de Estudiantes que se fundó en Colombia. Sus compañeros lo nombraron "Secretario Perpetuo" de la Federación; por ello, desde entonces Arciniegas estuvo en todas las actividades estudiantiles en Colombia.

Su acción estudiantil la unió al periodismo, iniciando con su periódico “Año Quinto" que hizo en 1916 en la Escuela Nacional de Comercio que regentaba el Rector, Doctor Guillermo Wickman. El joven Germán cursaba el Quinto año de Bachillerato. Este periódico tuvo gran demanda por las caricaturas, hechas por el joven Arciniegas, que aparecían en sus páginas de los Profesores y de sus compañeros. En el año 1917, cuando estaba en grado sexto, el último año de Bachillerato en la Escuela Nacional de Comercio, fundó su gaceta de cuatro páginas que llamó La Voz de la Juventud. El primer número lo imprimió en los Talleres del periódico conservador "La Sociedad", cuyo primer editorial lo dedicó a la intervención de los Estados Unidos en Panamá; y en el cual publicó la carta que le envió el historiador español Rafael Altamira, en que apoyaba el movimiento estudiantil colombiano. Fueron colaboradores los poetas Rafael Maya y León de Greiff. Su editorial lo tituló "La Unión de estudiantes", que inició con una frase de Renán: "La juventudes el descubrimiento de un horizonte nuevo que es la vida”. Incluyó citas de José Enrique Rodó y planteó la Reforma de las Escuelas.

\footnotetext{
${ }^{12}$ PUYANA MUTIS, Aura María. (2005): Vigencia y caducidad del Movimiento de Córdoba. 1918-1919. En la obra Movimientos Universitarios. América Latina Siglo XX. VARGAS, Olmedo, Tunja, Rudecolombia, pp. 141-151. Véase la obra de ZULUAGA GARCÉS, Olga Lucía y otros colaboradores, Modernización de los Sistemas Educativos Iberoamericanos. Siglo XX. Bogotá, Cooperativa Editorial Magisterio.
} 
En 1921 inició sus escritos en el periódico "ElTiempo", cuyo Director era el Dr. Eduardo Santos. Su carrera periodística la continuó en este periódico, en el cual dirigió la Sección editorial en 1928 y participó periodísticamente en las jornadas democráticas del 8 de junio de 1929. En 1932 fue nombrado Jefe de Redacción del Diario "El Tiempo". Al plantearse la candidatura de Eduardo Santos para la Presidencia de la República, Germán Arciniegas fue nombrado Director de "ElTiempo". Su actividad periodística fue permanente, colaborando con los periódicos de importancia en Colombia y en otros países de América Latina.

En el año 1921 organizó la primera huelga en la Universidad Nacional contra el nombramiento del nuevo Rector, el Doctor Alejandro Motta, a quien los estudiantes no conocían. Arciniegas actuó como Secretario de la Federación de Estudiantes. Se organizó una gran manifestación en mayo de 1921, pero antes de que ello ocurriera, la acción del Presidente Marco Fidel Suárez influyó para la renuncia del rector nombrado. ${ }^{13}$

El líder Germán Arciniegas y la Federación de Estudiantes respaldaron la primera huelga que hicieron los estudiantes de la Universidad de Antioquia en 1921, cuando se presentaron polémicas y protestas por la instalación del óleo de Don Fidel Cano, fundador de "El Espectador" en el Paraninfo de la Universidad, al lado del Sagrado Corazón de Jesús. Los católicos consideraron que no se podía colocar a la par el retrato de quien había sido excomulgado. Los estudiantes de Bogotá respaldaron a los estudiantes de la Universidad de Antioquia. El distintivo de antioqueños y bogotanos fue una cinta verde, el emblema de la Federación de Estudiantes. Muchos estudiantes, tanto en Medellín, como en Bogotá fueron a la cárcel.

Contaba el Maestro Arciniegas que a los miembros de la Junta Directiva de la Federación de Estudiantes, les correspondió afrontar los hechos del 8 de junio de 1929, cuando en la Plaza de Bolívar de Bogotá, fue herido gravemente el estudiante Gonzalo Bravo Pérez, acudido del Presidente Miguel Abadía Méndez, quien murió en la Clínica de Peña. La Federación de estudiantes organizó un funeral multitudinario y una agitación con todo lo que se vivía en unos días de crisis gubernamental. Este hecho de la muerte del estudiante se continúa celebrando anualmente en actos estudiantiles conmemorativos del 8 y 9 de junio. ${ }^{14}$

\footnotetext{
${ }^{13}$ Op., cit, pp. 89-130.

${ }^{14}$ Ibídem, pp. 95
} 


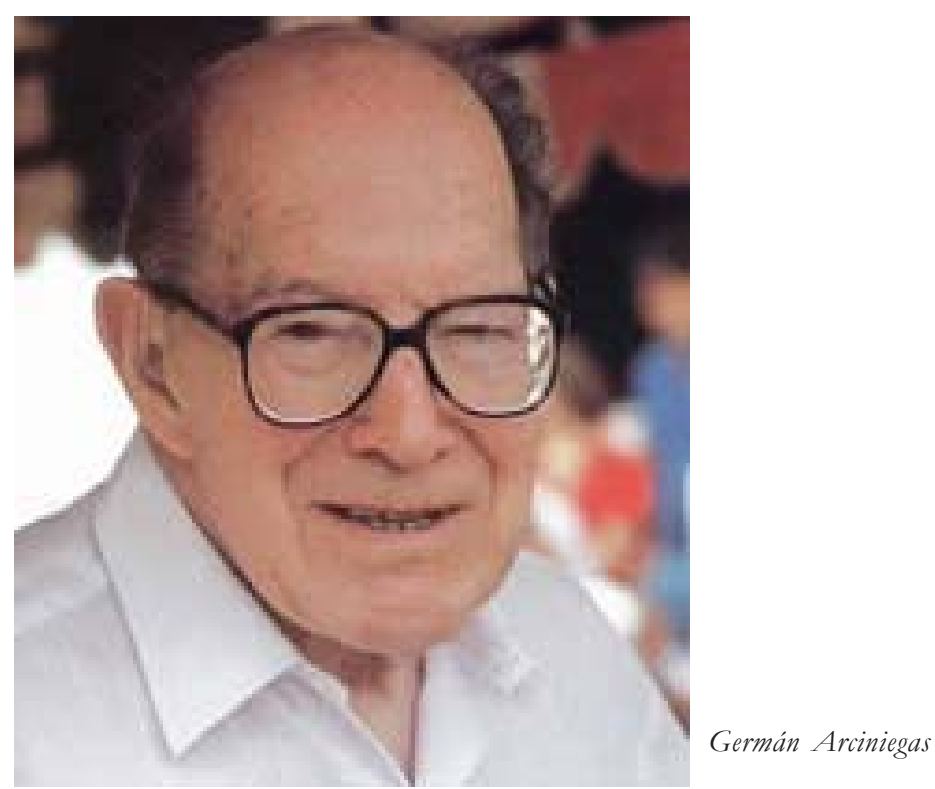

Sus antecedentes se encuentran en el Movimiento Trecemarcista del 13 de marzo de 1909, cuando los estudiantes bogotanos se rebelaron contra la Dictadura del Presidente Rafael Reyes. Fue el movimiento trecemarcista que culminó con la renuncia del Presidente Reyes. Uno de los dirigentes estudiantiles fue el estudiante Enrique Olaya Herrera, quien fue Presidente de Colombia entre los años 1930 a 1934 . Otros dirigentes trecemarcistas integraron el movimiento político del Republicanismo. ${ }^{15}$

La conspiración estudiantil en Colombia tiene sus orígenes remotos en el año 1794, cuando los estudiantes colocaron pasquines en las esquinas de Santa Fe de Bogotá. Fueron procesados los estudiantes Luis Gómez, Pablo José Uribe y José María Durán, alumnos del Colegio Mayor del Rosario y de San Bartolomé. También los movimientos estudiantiles se manifestaron en la Revolución Política de 1810, con la participación de los estudiantes del Rosario y de San Bartolomé en los hechos del 20 de julio de 1810, entre ellos, el chispero José María Carbonell y Francisco de Paula Santander, quien culminaba sus estudios de Derecho. ${ }^{16}$

Las agitaciones también las encontramos en la Década de la Gran Colombia cuando se manifestaron las polémicas entre los benthamistas y los

15 Sobre el movimiento estudiantil "Trecemarcista", véase la obra de RODRÍGUEZ, Gustavo Humberto. (1981): Olaya Herrera, político, estadista y caudillo. Bogotá, Banco de la República.

16 ACADEMIA COLOMBIANA DE HISTORIA. (1929): Causas célebres

a los precursores. Bogotá, Academia Colombiana de Historia, pp. 254-255. 
antibenthamistas. En el Colegio de San Bartolomé se manifestó un enfrentamiento entre los estudiantes que llevó a un autor a escribir una hoja volante sobre "El Cuchillo de San Bartolomé". En esos años de crisis grancolombiana, algunos estudiantes participaron en la Conspiración septembrina con la Dictadura de Bolívar en 1828.

Los estudiantes colombianos también participaron contra la Dictadura del General Tomás Cipriano de Mosquera en mayo de 1867. Algunos se organizaron militarmente para hacer guardia en el palacio presidencial y no permitir la ayuda de los artesanos que eran amigos de Mosquera. Los estudiantes defendieron la constitución y las leyes contra la dictadura. Los actos estudiantiles del 23 de mayo de 1867, los del 13 de marzo de 1909 y los del 8 y 9 de junio de 1929, son el reflejo de las actividades estudiantiles en sus relaciones con la política colombiana, liberal o conservadora. ${ }^{17}$

En el año 1922 se realizó el Congreso Nacional de Estudiantes en Medellín, el cual fue promovido por el estudiante Arciniegas, quien fue el delegado de la Federación Nacional de Estudiantes. En dicho Congreso se planteó la Reforma Universitaria para Colombia y se consolidó la organización de los estudiantes colombianos.

El dirigente estudiantil Germá Arciniegas en la década de los Veinte del siglo XX, se convirtió en un agitador universitario. En la revista "Universidad"; en la Secretaría Perpetua de la Federación Nacional de Estudiantes y en las diversas "Huelgas" que se hicieron en Colombia en la Década de los Veinte, siempre aparecía el dirigente estudiantil Arciniegas. Él era, según Abelardo Forero Benavides, "la eminencia gris" de todos los disturbios e inquietudes y el asesor intelectual del inconformismo de los estudiantes universitarios. Arciniegas salía a las calles agitando banderas y gritos. $^{18}$

${ }^{17}$ ALAMEDA OSPINA, Raúl. (2005): Los Movimientos estudiantiles y el movimiento político en Colombia. En: la obra Movimientos Universitarios. América Latina Siglo XX. VARGAS, Olmedo Tunja, Rudecolombia, pp. 65-76.

${ }^{18}$ CACÚA PRADA, Antonio. (1990b): Op.cit., p. 98. 


\section{Arciniegas y la Revista "Universidad"}

Cuando se organizó la Federación de Estudiantes en 1921, el joven dirigente Arciniegas decidió editar una revista quincenal que llamó “Universidad”. El 24 de febrero de 1921 apareció en Bogotá el No 1 de esta revista, cuyo Director fue Arciniegas y el administrador Julio González Concha. Se convirtió en la primera revista del mundo universitario, con críticas a la situación del país y de las Universidades, información universitaria y educativa en general. Diversas noticias y cuestiones estudiantiles y estudios profundos sobre sociología política, arte y ensayos en general de los grandes escritores de la época, señalando entre ellos a Diego Mendoza Pérez, Miguel Jiménez López, Luis López de Mesa, Augusto Ramírez Moreno, Juan Lozano y Lozano, Alberto Lleras Camargo, Silvio Villegas, Jorge Álvarez Lleras, Otto de Greiff, León de Greiff, Rafael Bernal Jiménez, Ramón Vinyes, Arciniegas, el Director, y muchos otros escritores. Esta revista se publicó en la casa Editorial Minerva.

En la portada de la revista "Universidad" encontramos caricaturas hechas por Ricardo Rendón; la primera es de Don Eduardo Esguerra Serrano, Presidente de la Federación de Estudiantes; la segunda fue dedicada a Don Roberto Andrade, Delegado al Congreso de Guayaquil. La quinta fue dedicada a Don Augusto Ramírez Moreno; la sexta a Don José Ignacio Castro, el Primer Vicepresidente de la Asamblea de Estudiantes; la séptima a Don Tomás Rueda Vargas, Rector del Gimnasio Moderno; la octava a Don Hernando de la Calle, de la Asamblea de Estudiantes; la novena dedicada a Don Julio González Concha de la Facultad de Ingeniería; la décima a Don Guillermo Londoño, Delegado de la II y a la III Asamblea de Estudiantes de la Facultad de Medicina. En otros números aparecen las revistas dedicadas al Dr. Carlos E. Restrepo, Francisco Bruno, Gustavo Esguerra Serrano Gustavo Santos, Francisco Montoya y otros.

La revista "Universidad”salía quincenalmente; tenía varias secciones: Semanario, Economía Nacional, Página femenina, los libros, vida universitaria, notas internacionales, vida parlamentaria y otras. Se suspendió en el No 34 del 20 de abril de 1922. Esa corresponde a la primera etapa, con grandes aportes para el desenvolvimiento de la labor universitaria.

En una carta del 28 de mayo de 1923, el escritor y educador mexicano José Vasconcelos, le envió al joven Germán Arciniegas, un mensaje a la juventud de Colombia. Gracias a su interés, con aprobación de la Federación de Estudiantes, el ideólogo mexicano fue aclamado 


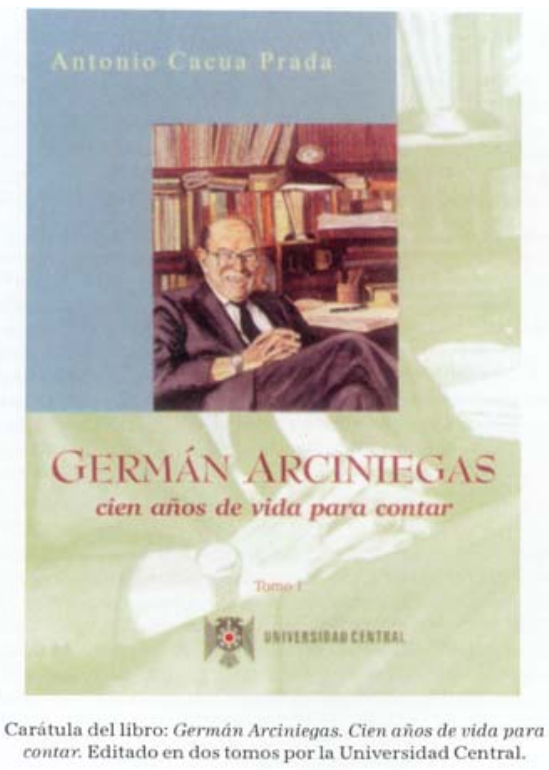

como "Maestro de la Juventud" en América. Este escritor y educador, fue quien transformó la educación, después de la Revolución Mexicana; estimuló el nacionalismo a través de los pintores muralistas (Rivera, Siqueiros y otros) y el ejemplo de "Maestro" para las generaciones hispanoamericanas.

La segunda etapa de la revista “Universidad", la inició el Maestro Arciniegas con el No 35, el 27 de junio de 1927. Fueron administradores: Hernando Téllez, Luís Alberto Gardeazábal y Roberto García Peña. Escribieron en esta nueva etapa: Víctor Raúl Haya de la Torre, Carlos Pellicer, Baldomero Sanín Cano, León de Greiff, Diego Mendoza Pérez, Carlos Lleras Restrepo, Tomás Cadavid Restrepo, Abel Carbonell, Luís Eduardo Nieto Caballero, Tomás Carrasquilla, Tomás Rueda Vargas, Rafael Bernal Jiménez, Armando Solano, Guillermo Valencia, Luís López de Mesa, Luis Augusto Cuervo, Gabriela Mistral, Alfonsina Storni, Leopoldo Lugones, Germán Arciniegas, el Director, y otros. En esta revista, el Maestro Arciniegas se interesó por estimular a la juventud con las nuevas ideas, en defensa de la libertad y la democracia. Esta revista "Universidad” alcanzó hasta el número 152 en el año 1929. Su cierre se debió a las dificultades económicas para su financiación. En esos días, el Maestro Arciniegas se desempeñó como Jefe de Redacción del Diario "El Tiempo"; asímismo, dirigió su sección editorial. $^{19}$

En su vida personal se destaca su matrimonio con la antioqueña Gabriela Vieira en Medellín, el 19 de noviembre de 1926, con quien tuvo dos hijas: Aurora Mercedes y Gabriela. Su esposa Gabriela, quien lo acompañó en todas sus actividades diplomáticas, políticas, docentes, académicas, etc., falleció el 4 de septiembre de 1996, después de una corta enfermedad respiratoria, tres años antes de la muerte del Maestro Arciniegas. Siempre se destacó como periodista: en el Diario "ElTiempo" de Bogotá; "El Nacional” de Caracas; el periódico "La Prensa” de Buenos Aires; " $A B C$ " de Madrid y otros diarios de Latinoamérica.

19 ARCINIEGAS, Germán.(1932):La Universidad Colombiana, proyecto de ley y exposicion de motivos presentado a la Cámara de Representantes por German Arciniegas, Bogotá, Imprenta Nacional. 


\section{Arciniegas y su actividad diplomática y política}

En las Décadas de los Treinta y los Cuarenta en el siglo XX, el Maestro Arciniegas se dedicó a la actividad diplomática y política, en los años cuando, con su influencia como Ministro de Educación, se consolidó la cultura colombiana. En 1929, el Maestro Germán Arciniegas con su esposa Gabriela se ubicaron en Nueva York. Posteriormente fue nombrado Cónsul de Colombia en Londres. Allí publicó su primera obra "El estudiante de la Mesa Redonda", que fue reconocida en el mundo europeo e hispanoamericano. Según sus ideas, no se entiende la Historia moderna y contemporánea, sin conocer la participación de los estudiantes universitarios.

Cuando el Liberalismo subió al poder en el año 1930 con la elección del Presidente Enrique Olaya Herrera, los dirigentes liberales resolvieron dar un renglón en la lista de Cámara a los estudiantes. Ellos eligieron al Maestro Germán Arciniegas, a quien le comisionaron la lucha en el Congreso Nacional por la Reforma Universitaria. Como un aporte a la educación, el Maestro Arciniegas se dedicó al Proyecto de Ley sobre la Reforma Universitaria, aprovechando las experiencias de Buenos Aires, México y las Universidades de París, Bruselas, Inglaterra y de otros países europeos. Así escribió su libro sobre la "Reforma Universitaria", buscando la autonomía universitaria. Lo apoyaron sus tres grandes amigos: Eduardo Santos, Alberto Lleras Camargo y Carlos Lleras Restrepo. El proyecto de gran profundidad y demasiado voluminoso no pasó en el Congreso Nacional, pues en él, se buscaba una autonomía universitaria, y especialmente una autonomía económica. El proyecto no tuvo un debate final. La autonomía universitaria no convenció ni a los conservadores, ni a liberales. Arciniegas publicó su libro "La Universidad Colombiana", con 192 páginas. Corresponde a su proyecto de ley y exposición de motivos presentados al Congreso Nacional. Posteriormente publicó su obra "Memorias de un Congresista". 20

Este dirigente estudiantil fue asignado a varias embajadas en América y Europa. En 1930 fue nombrado Vicecónsul de Colombia en Londres. Allí publicó su primer libro "El estudiante de la mesa redonda" en 1932. En 1939 fue nombrado Ministro Consejero de la Embajada de Colombia en Argentina. Desde cuando llegó a Buenos Aires, inició su colaboración en el

${ }^{20}$ Op. cit., p. 52. 

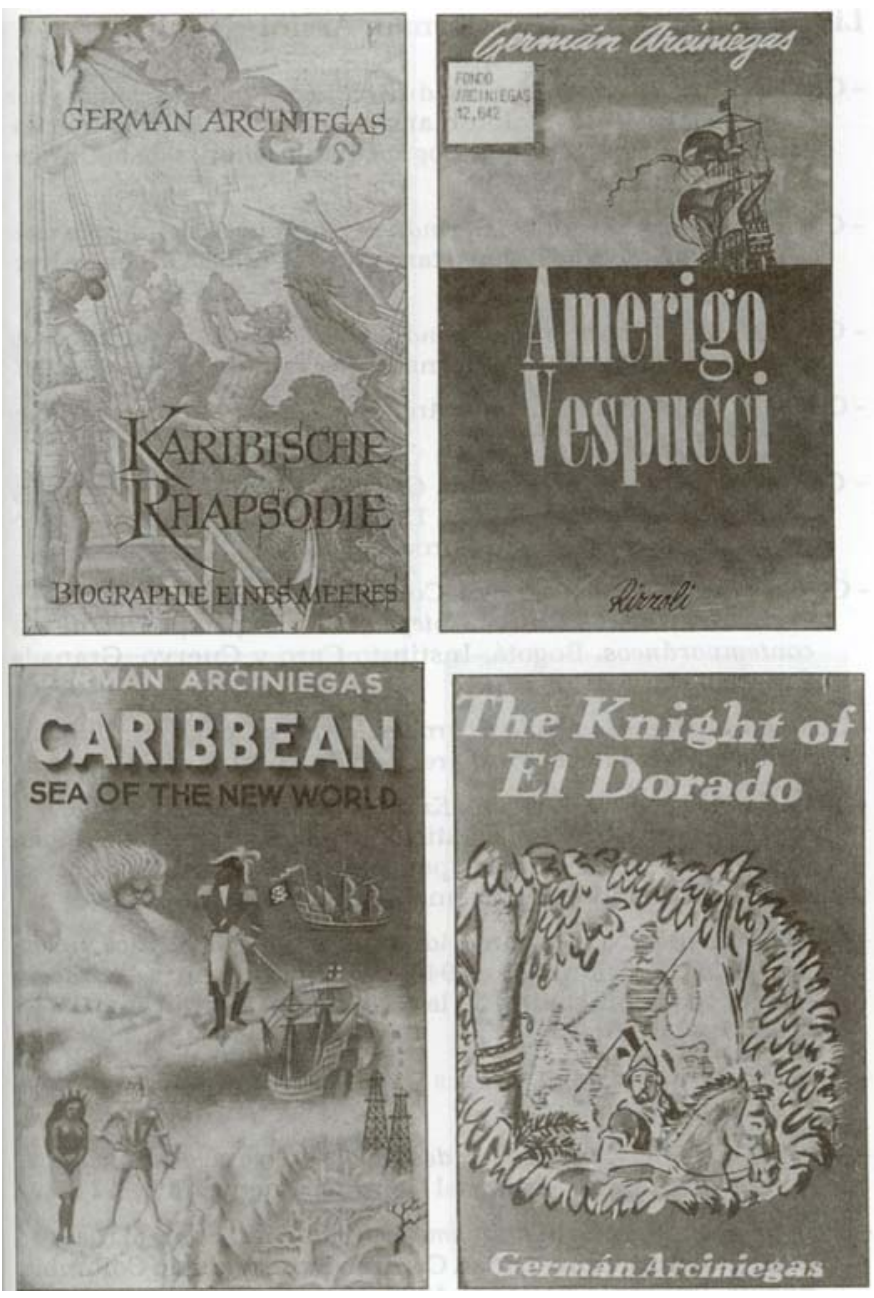

Diario "La Prensa”. En 1959 fue nombrado Embajador de Italia y posteriormente Embajador en Israel, en donde permaneció hasta 1962. En el año 1967 fue nombrado Embajador de Colombia en Venezuela. Con sus declaraciones de junio de 1970 como Embajador de Colombia, afirmando que tanto Bolívar como Sucre y Anzoátegui fueron los primeros indocumentados, es decir, que no requerían de papeles para pasar de un país a otro, ocasionó grandes polémicas y motivaron que se le declarase "persona no grata" en Venezuela. El 25 de noviembre de 1976 ingresó en solemne audiencia con su Santidad Paulo VI, como Embajador de Colombia ante el Vaticano. Ejerció su cargo hasta 1978. En Roma participó en la creación del "Centro di Studi Americanistici”. En esta experiencia diplomática conoció el mundo europeo, que plasmó en sus escritos históricos y literarios; asimismo, el mundo latinoamericano que estudió con vehemencia y señaló como la tierra de la democracia, pero con las fuerzas recurrentes de las dictaduras; por ello su tesis sobre América, entre la libertad y el miedo.

En varias Universidades de Latinoamérica, Estados Unidos y Europa, el Maestro Arciniegas en sus actividades diplomáticas y culturales se destacó por sus conferencias. En 1958 dictó una conferencia en San Salvador sobre "Los problemas de la Juventud hispanoamericana". En mayo de 1958 dictó la conferencia sobre "La lucha por la Democracia en Nuestra América” en Buenos Aires. El 20 de mayo de 1973 dictó su conferencia en el Colegio Nacional de México sobre el tema "Copérnico, un hijo de América", la cual fue publicada por dicha entidad. Otros temas en sus conferencias fueron los siguientes: "Cristóbal Colón y Américo Vespucio"; 
"La bella Simonetta, la primavera del Renacimiento", "Libertad de informacióny ética periodística". Sus conferencias fueron continuas y con variados temas en las principales ciudades latinoamericanas y europeas.

En su actividad política liberal, fue elegido dos veces a la Cámara de Representantes, en donde realizó una importante actividad congresista, especialmente con los asuntos relacionados con la educación y la cultura. En 1933 publicó su libro "Memorias de un Congresista", en el cual recopiló crónicas periodísticas sobre el parlamento colombiano. Asimismo, publicó su libro "Reforma Universitaria", con el proyecto de educación superior que presentó ante el Congreso Nacional. En el año 1938 fue reelecto Representante a la Cámara por el Partido Liberal. Posteriormente en el año 1958 fue elegido Senador de la República.

\section{Germán Arciniegas, Ministro de Educación, gran educador y docente universitario}

El Presidente Eduardo Santos lo nombró Ministro de Educación, cargo que ocupó en los años 1941-1942. En este cargo apoyó con dinamismo la cultura y la educación en Colombia. Fortaleció la Escuela Normal Superior de Colombia, colaborando con la actividad dinámica de su rector, el Dr. José Francisco Socarrás. Trajo grandes profesores e investigadores procedentes de España, Francia y Alemania, señalando entre ellos a los científicos Paul Rivet, Justus Wolfran Schottelius, Rudolf Hommes, Rafael Altamira, José María Ots Capdequi, José de Recasens, Ernesto Gull, Gerhart Masur, Urbano González de la Calle, Pablo Vila y otros. Ellos hicieron verdadera "Escuela" en antropología, arqueología, filología, estudios clásicos lingüística, historia, geografía y otras. ${ }^{21}$

El Ministro Arciniegas, con la colaboración del filólogo español Urbano González de la Calle, el Padre Félix Restrepo y el humanista José Manuel Rivas Sacconi, creó en el año 1942, el Instituto Caro y Cuervo, el organismo científico de la Lengua castellana en Colombia. Asimismo, con las orientaciones del etnólogo francés Paul Rivet, creó el Instituto Etnológico Nacional, que actualmente es el Instituto Colombiano de Antropología e Historia. Se interesó por la edición de obras en la llamada Biblioteca Popular y el apoyo a las revistas literarias y científicas. Le correspondió la

${ }^{21}$ OCAMPO LÓPEZ, Javier. (1978): Educación, Humanismo y Ciencia. Tunja, Universidad Pedagógica y Tecnológica de Colombia. 


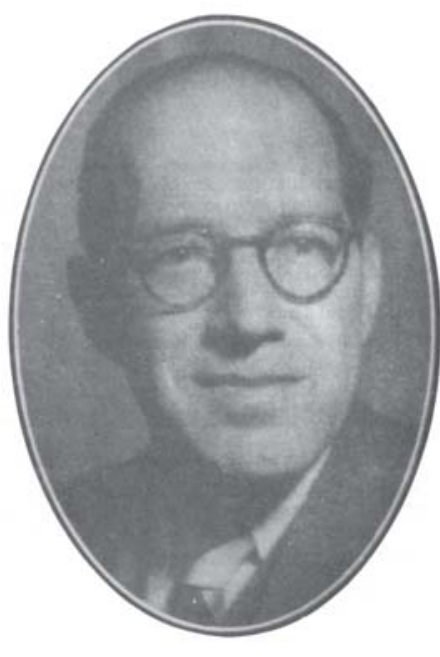

Maestro Germán Arciniegas creación del Museo Nacional y el Museo de Arte Colonial de Bogotá. Se convirtió en uno de los períodos de mayor avanzada en la educación y la cultura en Colombia.

Posteriormente en los años 1945 y 1946 fue Ministro de Educación en el Gobierno del Presidente Alberto Lleras Camargo. Cuando subió el Régimen conservador al poder en 1946, el Maestro Arciniegas salió para Francia y se radicó por unos años como Profesor visitante en varias Universidades de los Estados Unidos y como viajero por toda América, recalcando siempre la idea de la libertad y la democracia contra los despotismos, las tiranías y las dictaduras.

El Maestro Germán Arciniegas en su vida intelectual fue siempre un gran docente universitario, un GRAN MAESTRO. Cuando culminó sus estudios universitarios en el año 1925, fue nombrado Profesor de Sociología en la Universidad Nacional. En 1942 dictó cursos de Historia Sudamericana en la Universidad de Columbia. En junio y julio de 1943 dictó cursos en el Institute of International Relations en Oakland, California. En 1944 fue Profesor visitante del Comité Americano por la Libertad de la Cultura, en el cual fue Vicepresidente en 1944. En el año 1944 fue Profesor visitante en la Universidad de Chicago. En 1947 inició su actividad docente en Columbia University en Nueva York. En 1948 fue nombrado catedrático de Literatura hispanoamericana; en esta Universidad permaneció hasta 1959. Allí conoció y tuvo relaciones de amistad y humanística con los Profesores Menéndez Pidal, Américo Castro, Jorge Guillén y Pedro Salinas. Sus cursos en Columbia University en 1955 se dedicaron a los temas "El ensayo en Latinoamérica", "La Literatura del Descubrimiento". En el año 1956 su curso fue sobre "Los conquistadores a través de la Literatura del siglo XVI".

El Maestro Arciniegas tuvo amistad con grandes escritores del Mundo. En Italia cultivó su amistad con el escritor Giovanni Papini; tuvo amistad con los escritores Rafael Altamira, el Maestro mexicano José Vasconcelos, a quien llamó "El Maestro de la Juventud de América". En la Década de los Cuarenta tuvo importantes relaciones con Pedro Henríquez Ureña, Amado Alonso, Francisco Ayala, Victoria Ocampo, Stefan Sweig, Alfonso Reyes, Tomás Mann, Juan Marinero, Jules Romaní y otros. En 1956 participó con Jorge Luis Borges, Francisco Romero, Victoria Ocampo, H.A. Murena, Adolfo Bioy, Rosa Charles y otros 
escritores en un debate sobre las dictaduras en Latinoamérica en la "Revista Sur".22

El 2 de junio de 1957, el Maestro Arciniegas regresó a Colombia, después de 10 años de exilio político, para la reapertura del periódico "ElTiempo", clausurado durante el Gobierno del Presidente Gustavo Rojas Pinilla en 1955.

En sus intervenciones a nivel mundial, el Maestro Arciniegas se destacó por las polémicas y debates. En las Décadas de los Veinte y los Treinta del siglo XX, se destacaron sus polémicas sobre la Reforma Universitaria. En la Década de los Cincuenta se hizo famosa su polémica sobre las Dictaduras en América, "entre la libertad y el miedo"; fue considerado el escritor subversivo por los dictadores de Centroamérica y el Caribe. Se destacaron sus polémicas históricas sobre el Descubrimiento de América, Cristóbal Colón y Américo Vespucio; la polémica sobre América en Europa, contra el artículo de Papini. El debate sobre Bolívar y Santander; el debate sobre la Nueva Historia en 1989, con los historiadores Germán Colmenares, Jorge Orlando Melo, Salomón Kalmanovitz y otros.

En el año 1979 el Maestro Germán Arciniegas regresó a Colombia como Decano de la Facultad de Filosofía y Letras de la Universidad de Los Andes de Bogotá. En esta Universidad fue célebre su CÁTEDRA $D E A M E ́ R I C A$, que fue permanente hasta unos pocos años antes de su muerte. Siempre fue muy acogida por los estudiantes y profesores que asistían permanentemente, pues sus temas de gran filosofía, profundidad y erudición eran siempre muy variados. Allí fundó la revista "Correo de Los Andes" que terminó en el No 58 de 1989.

Su pasión por la educación y la cultura la precisamos también a través de su gestión cultural y en la Dirección de varias revistas, señalando entre ellas, la "Revista de América", "Revista de las Indias", "Cuadernos Americanos", "El Correo de los Andes" y otras. En la vida académica registramos su actividad constante desde la Década de los Cuarenta. El 8 de febrero de 1946 fue elegido Miembro de Número de la Academia Colombiana de la Lengua, Silla K; se recibió el 14 de agosto de 1947. El 11 de julio de 1946, el Maestro Arciniegas ingresó como Miembro de Número de la Academia Colombiana de Historia. Su discurso de ingreso 


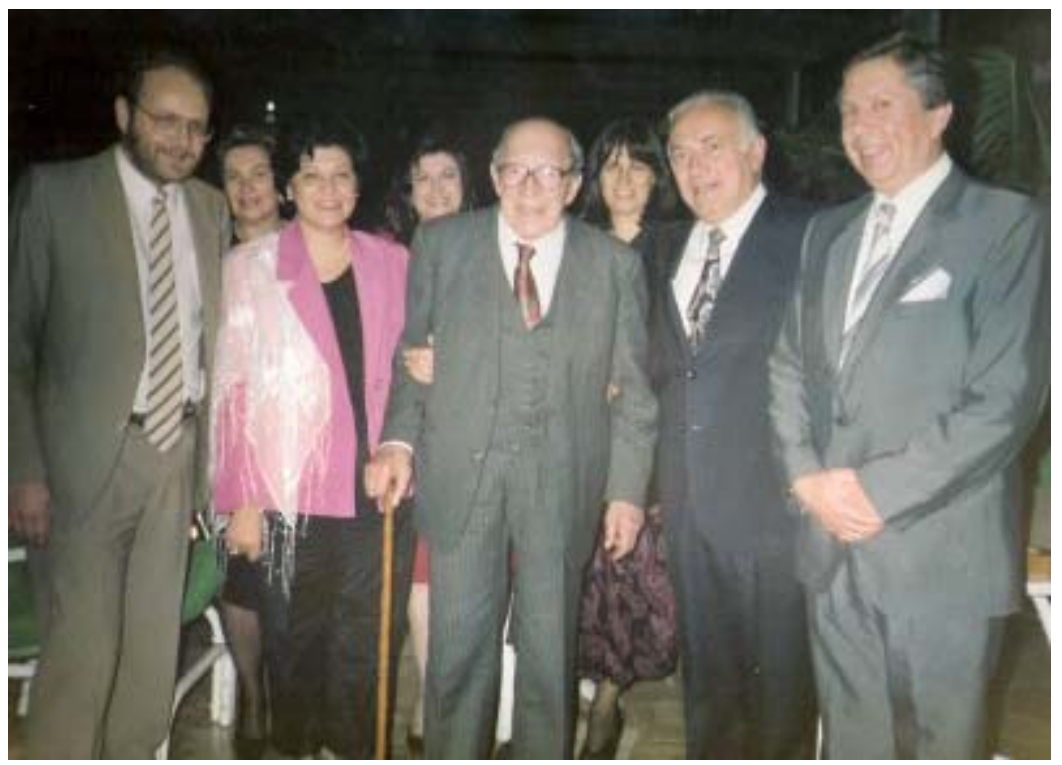

Germán Arciniegas en compañia de sus amigos.

versó sobre el tema "La novela y la Historia"; le respondió el Presidente Eduardo Santos. El 7 de noviembre de 1947, fue elegido Miembro correspondiente de la Academia Española de la Lengua, con la presentación que le hicieron los escritores Eugenio D`Ors, Wenceslao Fernández Flórez y Emilio García Gómez. Asimismo, fue miembro de otras Academias e instituciones culturales de Colombia, de América Latina y del mundo. En 1973 participó en México en el Congreso de Academias de la Lengua, presidido por el escritor Dámaso Alonso.

En el año 1980 fue elegido Presidente de la Academia Colombiana de Historia, cargo que ejerció durante 14 años hasta 1994; cuando le sucedió el Dr. Luis Duque Gómez. El 3 de febrero de 1989 fue nombrado Presidente vitalicio de la Academia Colombiana de Letras y Filosofía. En el año 1985 entró a presidir la Comisión Colombiana para el Quinto Centenario del Descubrimiento de América. Sin embargo, en noviembre de 1992 fue destituído por el Presidente César Gaviria como Presidente de la Comisión preparatoria del Descubrimiento de América, debido a presiones del Gobierno español, ante su visión americanista, contraria a los intereses de las instituciones españolas.

El Maestro Arciniegas recibió las más altas condecoraciones de Colombia y América. Recibió el Premio Cabot de Periodismo, Premio Alberto Sarmiento de Prensa de Buenos Aires, Premio Internacional Hammarskjold del periodismo y diplomacia, Premio Internacional Madonnina de Milán. El 25 de octubre de 1989, The Americas 
Foundation le otorgó el título de "Hombre de las Américas". Otras condecoraciones y reconocimientos: Condecoraciones "Libertador" y "Andrés Bello" de Venezuela, "O’Higgins de Chile, Medalla al Mérito de Italia. "Vasco Núñez de Balboa" de Panamá. El Premio de las Américas" otorgado por The American Foundation. Medalla de reconocimiento a su obra intelectual, otorgada por el Instituto Colombiano de Cultura en 1990. Medalla del "Hombre de las Leyes" otorgada por la Sociedad Santanderista de Colombia en 1990.. Premio "San Giusepe Piero Bargellini”" de Florencia, Italia en 1991. Premio Internazionale Luige Prette de Roma en 1992. Premio Nacional Simón Bolívar, julio 24 de 1992 en Bogotá. Premio de las Américas de la Organización Universitaria Interamericana en 1992. Premio “Alfonso Reyes" de México, en 1994. Premio Planeta de Historia, otorgado en 1996. El Maestro Germán Arciniegas falleció en Bogotá el 30 de noviembre de 1999, a su edad de 99 años. ${ }^{23}$

\section{E1 Maestro Arciniegas y el Ensayismo latinoamericano. Sus principales obras}

El Maestro Germán Arciniegas representa el ensayismo americano a nivel mundial. Fue el ensayista de un continente de grandes contrastes, incertidumbres, discusiones y problemas. En sí mismo, América es un ensayo y un continente de grandes polémicas, afirmó el Maestro.

En sus ensayos manifestó su pasión por reflexionar sobre la ontología de Nuestra América Latina: su razón de ser, su esencia y su presencia ante el mundo. En su pensamiento buscó la autenticidad y la identidad de América en lo cultural, sociológico, histórico, en sus proyecciones en la cultura universal y en el proceso histórico y dinámico de las civilizaciones.

El sentido de lo americano es la constante en sus ideas, y su defensa de la libertad y la democracia, contra todo tipo de despotismo, dictaduras y de esclavismo en todas sus manifestaciones. En sus ensayos se preocupó por la participación del pueblo en la Historia: las gentes del común que defendieron sus intereses en las revoluciones populares.

El ensayo es el género literario más natural del escritor americanista como lo hizo el Maestro Germán Arciniegas, porque a través de él se discuten los problemas, se hacen las polémicas y se plantean posibles 
soluciones. Los caminos que llevan al ensayo histórico son medios a través de los cuales la Historia se realiza. Es con el rigor de la ciencia de la Historia en el análisis de los hechos acaecidos en el pasado, con el símbolo del arte, la precisión del derecho, los datos y análisis de la sociología, los estudios sobre el Hombre y la Cultura con los aportes de la Antropología y la Etnología, la Educación; los análisis profundos de la Economía, la Política y las demás Ciencias Humanas, como el filósofo de la Historia o historiador ensayista escribe sus ensayos históricos, dando especial importancia a la Hermenéutica histórica.

El Maestro Arciniegas en sus ensayos interpretativos llevó en su pensamiento y acción la responsabilidad del filósofo de la Historia, del investigador que se preocupa por el análisis de los hechos históricos de América, el movimiento de las fuerzas internas, externas y tendenciales del Nuevo Mundo en su relación con el proceso civilizatorio universal. Fue el filósofo de la Historia de América, quien en sus estudios llevó como meta la búsqueda de la verdad histórica y como camino la investigación documental, crítica interna y externa, hilvanación de los acontecimientos, hechos individuales y colectivos, instituciones, factores condicionantes, estructuras temporales, fuerzas históricas y otros elementos para la comprensión integral de lo histórico, e interpretación de la dinámica de América en el espacio y en el tiempo.

El Maestro Germán Arciniegas como ensayista historiador llega a la Historia comprobando la unicidad de lo histórico: de adelante hacia atrás, o de atrás hacia adelante, en un perpetuo remontarse o aventurarse. Pero lo más importante en su obra como filósofo historiador, es su preocupación por el PRESENTE, pues su análisis del pasado siempre tiene relación con el presente. Para el ensayista historiador, el tiempo no existe en forma estática, sino dinámica, en esa relación del presente hacia el pasado y el futuro en unicidad, en la Unidad del Devenir. El Maestro Germán Arciniegas como ensayista historiador, analizó el pasado en sus relaciones con el presente. El proceso histórico de América en sus cinco siglos del "Encuentro de Culturas", no le interesó en forma estática, sino dinámica; no en el pasado solamente, sino en lo que tiene de actual y de eterno. Esa América mágica; ese continente de siete colores; esa tierra de la libertad y la democracia, debe ser interpretada en el proceso de cinco siglos para medir sus tendencias históricas, sus rasgos y caracteres más significativos y su presencia grande en la Historia Universal.

El ensayo en América no es un divertimiento literario, sino la reflexión obligada a los problemas que cada época nos impone. Los grandes 
pensadores americanistas como los colombianos Germán Arciniegas, Baldomero Sanín Cano, Carlos Arturo Torres, Luis López de Mesa, Luis Eduardo Nieto Caballero, Antonio García, Indalecio Liévano Aguirre, Eduardo Caballero Calderón, Otto Morales Benítez, Jaime Jaramillo Uribe y otros. En México, los escritores José Vasconcelos, Justo Sierra, Alfonso Reyes, Samuel Ramos, Leopoldo Zea, el Maestro José Gaos y Octavio Paz, entre otros. En Argentina, los ensayistas Domingo Faustino Sarmiento, Francisco Romero, José Luis Romero y otros. En el Perú los escritores José Carlos Mariátegui y Víctor Raúl Haya de la Torre; el uruguayo José Enrique Rodó; En Venezuela los escritores Andrés Bello, Cecilio Acosta, Rómulo Gallegos y Arturo Uslar Pietri, entre otros; en Cuba, José Martí; en Puerto Rico, Eugenio María de Hostos; en Chile, Francisco Bilbao; el ecuatoriano Juan Montalvo y otros, quienes fueron ensayistas-filósofos por naturaleza en este mundo americano. ${ }^{24}$

El Maestro Germán Arciniegas publicó numerosas obras, que lo consagraron como uno de los más grandes escritores colombianos en el siglo XX. Su primera obra que publicó en 1932 fue "ElEstudiante de la Mesa redonda" (Madrid, Juan Pueyo, 248 pgs. Y otras ediciones de Santiago de Chile, Buenos Aires y Bogotá, con las cuales fue muy conocido en el mundo universitario. Y sobre la Educación, destacamos sus obras "Universidad Colombiana"(Bogotá, Imprenta Nacional, 1932) y "Memorias de un Congresista"( Bogotá, Editorial Cromos, 1933), en el cual informa sobre sus proyectos sobre la Reforma Educativa Universitaria. Asimismo, su obra "Cuadernos de un estudiante americano", publicado en Ediciones Uniandes y Educar Cultural Recreativa en 1994.

Entre sus obras con temática de América, señalamos las siguientes: "América Tierra Firme”, publicada en 1937 en la Editorial Ercilla de Santiago de Chile, y posteriormente en la Editorial Losada en Buenos Aires en 1944; fue la obra que más fue consultada en Latinoamérica. Su obra "Estepueblo de América”, publicada en México en el Fondo de Cultura Económica en 1945; "Biografía del Caribe", publicada en la Editorial Sudamericana en 1945. "Entre la Libertady el Miedo", publicada en México en la Editorial Cultura en 1952; fue la obra que señaló el problema de las dictaduras y la violencia en América Latina; fue la más perseguida por los dictadores de Centroamérica y el Caribe; alcanzó a 10 ediciones. "Nueva Imagen del Caribe" (1970). "El

${ }^{24}$ COBO BORDA, Juan Gustavo. (1990): Cronología y Bibliografía. Bogotá, Ed. Planeta. Véase la revista de la Biblioteca Pública Piloto de Medellín para América Latina: Germán Arciniegas Estudiante de América. Exposición documental. Coordinación general de Gloria Inés Palomino Londoño, Directora de la Biblioteca. Medellín, 1997. Asímismo la obra de OCAMPO LÓPEZ, Javier , Historia Ideas de Integración de América Latina, pp. 267-287. 


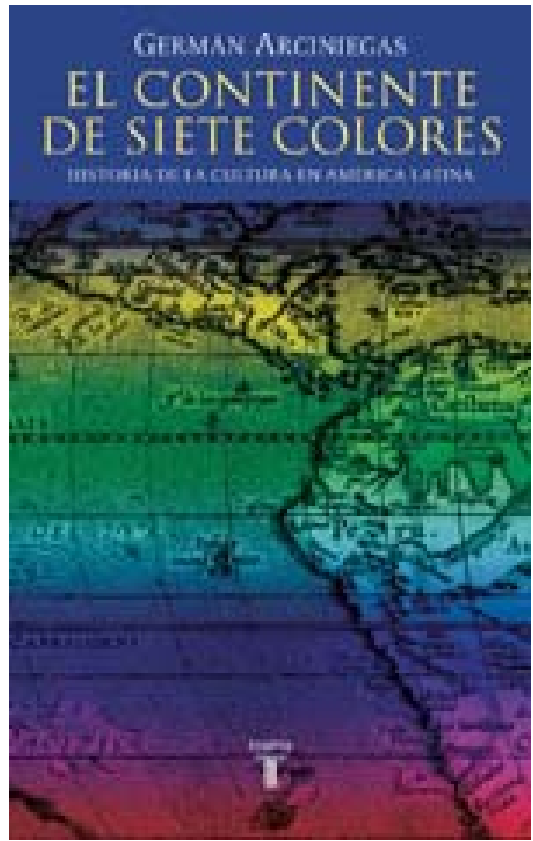

Continente de Siete Colores"(Historia de la Cultura en América Latina), publicada en la Editorial Suramericana de Buenos Aires en 1965. "América Mágica-Los Hombres y los Meses", publicada en la Editorial Suramericana en Buenos Aires en 1959. "América Mágica-Las mujeres y las horas", publicada en la Editorial Suramericana en 1961. "América en Europa"(1975). "El revés de la Historia"(1980), "Galileo mira a América” (1977), "Los Pinos Nuevos" (Diario de un sonámbulo enamorado), publicado en el IDESIL, Editorial Bolivariana Internacional en el año 1982, 515 pgs. "Centralismo europeoy Federalismo americano" (1985). "Con América nace la Historia" (1990). "América es otra cosa" (1992), "El Mundo cambió en América", (1993). "América Ladina", publicada en México en el Fondo de Cultura Económica en 1993, con textos de Arciniegas, recopilados por Juan Gustavo Cobo Borda. "América nació entre libros", publicado en 1996 por la Presidencia de la República (2 tomos). Asimismo, numerosos artículos americanistas.

Sobre la temática del Descubrimiento y Conquista de América, destacamos sus obras: “Jiménez de Quesada”, publicada en la Editorial ABC de Bogotá en 1939. "Los Alemanes en la Conquista de América”, publicada en la Editorial Losada en 1941. "El Caballero de El Dorado", publicada en la Editorial Losada de Buenos Aires en 1959 y posteriormente en Madrid en la Revista de Occidente en 1969. Su obra" Amérigo y el Nuevo Mundo", publicada en la Editorial Hermes en México-Buenos Aires en 1955. "El Mundo de la Bella Simonetta", publicada en la Editorial Sudamericana en Buenos Aires en 1962; la obra "El Embajador", un libro sobre la vida de Guido Antonio Vespucci, tío de Amérigo Vespuccio, ambientado en la Italia del Papa Sixto, Maquiavelo, Savonarola y Colón; publicada en 1990 y otras.

Sobre la temática de la Revolución de Independencia, señalamos las siguientes obras: "Los Comuneros"(1938), "20 mil Comuneros hacia Santafe"" (1981), "Colombia: Itinerario y espíritu de la Independencia" (1969), "Simón Bolivar"(1980), "Bolivary la Revolución”(1984), "Bolivar: Cartagena 1812, Santa Marta 1830" (1980), "Bolivar, el Hombre de la Gloria" (1983), "Bolivar, de San Jacinto a Santa Marta" (Juventudy muerte del Libertador), (1988). "ElLibertador y la guerrillera"(1990), "Bolivary Santander, vidas paralelas" (1995), "El Libro de Oro de Santander", "El Creador civil de la República" y numerosos estudios históricos publicados en las Revistas de Historia y en "El Correo de Los Andes". 
Sobre el pensamiento de grandes escritores y obras de artistas, mencionamos las siguientes: "ElPensamiento vivo de Andrés Bello" publicado en la Editorial Losada de Buenos Aires, en la Biblioteca del pensamiento vivo en 1946. "Genio y figura de Jorge Isaacs", publicado en Buenos Aires en la Editorial Eudeba en 1967. “Antología de León de Greiff”, publicado en Colcultura en 1976. "Fernando Lorenzana" (Recuerdos de su vida) publicado en el Instituto Caro y Cuervo en 1978. "Fernando Botero" (1979).

Otras obras del Maestro Arciniegas: "Transparencias de Colombia", publicada por el Instituto Colombiano de Cultura en 1973 (2 vols.). "Colombia", publicada en Washington en la Unión Panamericana (1962), "Italia, guía para vagabundos"(1957), "Roma secretísima"(1972), "De Pío XII a Juan Pablo II. Cinco papas que han conmovido al mundo"(1986), "Estancia en Rumania",(1974), "Entre el Mar Rojo y el Mar Muerto. Guia de Israel" (1964), "En el país de los rascacielosy las zanahorias"(1945), "The Green Continent", "Diario de un peatón" (1936), "Qué haremos con la Historia" (1940), "ElZancudo-Introducción a la Historia de la Caricatura en Colombia" (1975), "En medio del camino de la vida"(1984), "Cosas del Pueblo. Crónicas de historia vulgar" (1962). "Nuevo Diario de Noê" (1969), "Medio Mundo entre un zapato"(1969), "Páginas escogidas", "Gatos, patos, armadillo y otros seres bumanos" publicado por la Presidencia de la República en 1994. "Páginas escogidas", publicada en la Editorial Gredos de Madrid en 1975 y otras. ${ }^{25}$

El Maestro Germán Arciniegas fue Director de varias revistas. La revista "Universidad", desde 1922 hasta 1929. Desde enero de 1939 hasta mayo de 1944 dirigió la "Revista de las Indias", que se editó en Bogotá en el Ministerio de Educación, desde el No 21 en enero de 1939, hasta el No 65 en mayo de 1944. En el año 1945 dirigió junto con Roberto García Peña, la "Revista de América", publicación mensual de "ElTiempo"; 81 números entre 1945 y 1957. En el año 1945 inició su colaboración con la Revista "Cuadernos Americanos” de México, dirigida por Jesús Silva Herzog. Entre 1945 y 1978 aparecieron allí 20 artículos suyos, con temas sobre Mariátegui, Haya de la Torre, Alfonso Reyes, Rómulo Gallegos y otros. En 1963 fue nombrado Director de la revista "Cuadernos", fundada en París en 1953; la dirigió desde febrero de1963 hasta septiembre de 1965, cuando esta revista concluyó con el No 100. En 1974 fue encargado de la sección mensual de "Amerique Latine" de la "Revue des deux mondes"de París. En noviembre de 1979 fundó la revista "Correo de Los Andes", que terminó en 1989 con su número 58, considerada como una de las revistas culturales más importantes de Colombia en la segunda mitad del siglo XX.

\footnotetext{
${ }^{25}$ Ibídem.,p. 27
} 
En sus ensayos y artículos de revistas y periódicos, el Maestro Arciniegas luchó con vehemencia por la LIBERTAD. En 1943 fue nombrado Vicepresidente del Comité Americano por la Libertad de la Cultura. En 1951 colaboró con el libro "Freedom and Culture", patrocinado por la UNESCO. Colaboró junto con Julian Huxley, Jean Piaget, Rex Warner y otros. Participó con su estudio "Culture-a buman right".

\section{El Maestro Germán Arciniegas y sus ideas sobre la identidad de América}

En sus numerosos escritos, el Maestro Arciniegas se preocupó por estudiar la identidad de Nuestra América, en sus relaciones directas entre el mundo socio-cultural indígena y las culturas europeas y africanas. Como periodista e historiador, el Maestro Arciniegas siempre relacionó el presente con el pasado histórico; fue el auscultador de la cultura de cada lugar del mundo por donde pasó como "mirador” en Tenochtitlán, en Machu Picchu, en Tiahuanaco; ante el Barroco hispanoamericano en Quito, México y Lima; ante el Mundo del Caribe, en Los Andes, en las Pampas, etc. Se preocupó por ofrecer una visión contemporánea de Europa para encontrar en ella las raíces culturales de Nuestra América. En cada lugar europeo, obra arquitectónica, monumento y estilo de las ciudades europeas, encontraba la relación directa con el mundo americano. ${ }^{26}$

El Maestro Arciniegas se interesó por el estudio de las repercusiones de América en el Mundo, destacando los aportes del Nuevo Continente y los grandes cambios económicos, sociales, políticos y culturales en la Humanidad, como consecuencia de la aculturación europeo-americana. En sus obras, también se interesó por analizar el mestizaje como resultado de las relaciones indígenas, europeas y africanas, para dar como resultado un Mundo Nuevo. Una América nuestra que consolidó las repúblicas y la democracia, cuando en Europa se fortalecían las monarquías y se luchaba por afianzar los Imperios de Ultramar.

Una reflexión del Maestro Arciniegas sobre el Nuevo Continente, lo llevó a diferenciar cuatro Américas: La América Indoespañola, la América portuguesa (Brasil), la América Inglesa (Estados Unidos) y la América Anglofrancesa (Canadá). ¿Y cuáles son los aportes de las cuatro Américas

${ }^{26}$ ARCINIEGAS, Germán. (1982): Los Pinos Nuevos. Diario de un Sonámbulo

Enamorado, Tunja, Editorial Bolivariana Internacional. 
a la cultura universal?. El Maestro Arciniegas señala el surgimiento de un nuevo concepto de la vida civil y el haber consolidado una filosofía política que acabó por dominar el mundo del antiguo régimen monárquico. ${ }^{27}$

En la búsqueda de la identidad latinoamericana, el Maestro Germán Arciniegas señaló los rasgos propios de esta área del continente americano en relación con el mundo: una tierra mágica y un pueblo de gran desarrollo cultural en su desenvolvimiento histórico, en donde se encuentran los aportes de la cultura universal; una tierra de libertad y despotismo, en donde "en ocasiones habla el pueblo, y en otras el dictador".

Arciniegas consideró que en la dinámica histórica de América podemos encontrar varias tendencias que se proyectan en su esencia: América, tierra de la libertad; América, tierra de la democracia; América, tierra de la república; América, tierra de las revoluciones y América, tierra de lo nuevo. Estas tendencias se han convertido en permanencias que proyectan el espíritu americano en el plano mundial. Son la expresión de su filosofía que ha penetrado profundamente en la mentalidad colectiva de los latinoamericanos.

Una preocupación vehemente en el pensamiento y en la acción del Maestro Germán Arciniegas fue la Americanidad en la Libertad. Es el pensamiento de un americanista y humanista que defiende las libertades individuales y sociales, contra todo tipo de opresión, represión, autoritarismo y despotismo, tanto de la derecha conservadora y de los dictadores, como de la izquierda socializante. Para el ensayista humanista, la lucha por la libertad contra el despotismo se convierte en una esperanza contra el miedo.

El antropocentrismo de la Ilustración legó a América la lucha por la libertad y la defensa de los derechos naturales e inalienables de los individuos; la soberanía popular y la lucha por el establecimiento y vigencia de la democracia contra la monarquía y el orden señorial. El hombre debe buscar su "libertad" para disfrutar del mayor bienestar sobre la tierra; fue el ideario que transmitieron los filósofos de la Ilustración a los americanos. Era el regreso al humanismo y a la visión antropocéntrica, en la cual la razón de ser del hombre en el mundo debe ser la búsqueda de la libertad, los derechos naturales, la igualdad y el progreso de la sociedad.

${ }^{27}$ ARCINIEGAS, Germán. (1966): Las Cuatro Américas. En la obra coordinada por HANKE, Lewis, ¿Tienen las Américas una Historia común?, México, Editorial Diana, pp. 249-261. 


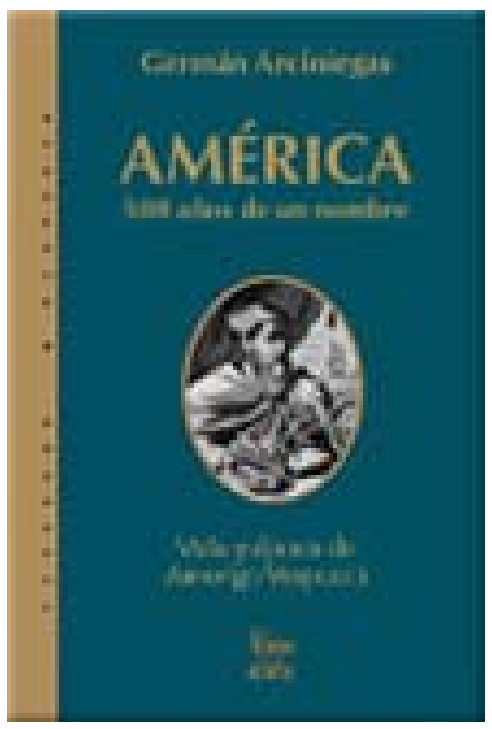

Las luchas por la obtención de la libertad y los derechos inalienables de los hombres sirvieron a los criollos hispanoamericanos para atacar todo signo de opresión y dominio colonial. Esta lucha debía ser radical para obtener el camino de las estructuras de la sociedad y la liberación de la dependencia colonial en relación con España.

Las ideas sobre la libertad en América están relacionadas directamente con los Derechos del Hombre, los cuales fueron traducidos y publicados en la Nueva Granada por el criollo santafereño Don Antonio Nariño. Según este documento que siguió las ideas defendidas en Estados Unidos y Francia, se reconocieron cuatro derechos fundamentales a los individuos: libertad, igualdad, propiedad y seguridad. Los hombres son libres e iguales y tienen derechos naturales e inalienables, entre los cuales figuran la libertad, el goce de la vida, la propiedad y la búsqueda de la felicidad. Son los derechos dirigidos a proteger al hombre como miembro de la sociedad. Precisamente para garantizar estos derechos, los hombres establecieron los gobiernos, los cuales derivan de los justos poderes concedidos por el libre consentimiento y la voluntad popular.

El Maestro Germán Arciniegas fue el gran defensor de la Americanidad, pero en la Libertad. Luchó contra las dictaduras de Centroamérica y el Caribe y los gobiernos militares de América Latina, en unas décadas cuando Nuestra América fluctuaba "Entre la Libertady el miedo", como así tituló su obra publicada en el año 1952. Este libro fue prohibido en las repúblicas de los dictadores y se introdujo clandestinamente en la Argentina. Su lucha fue con el ensayo y la gran polémica, sus ideas, sentimientos y actitudes se enfrentaron a la opresión, la represión, el terrorismo y el pregón de la muerte de los sátrapas que pululaban en América amparados por el imperialismo y los grupos dominantes en los países totalitarios. Sus argumentos en defensa de la libertad fueron conocidos en el mundo, como la expresión del "Colombiano universal", "El Hombre de las Américas" y el "Caballero de la Libertad”. Según sus ideas: América es la tierra de la democracia, el sufragio universal, de los derechos humanos y del civilismo. América es la tierra de la república y la "Tierra de lo nuevo". América es la tierra del humanismo y el escenario de la lucha contra el autoritarismo y la represión. $^{28}$

En su discurso "Hablando de Américas", cuando recibió el Premio de las Américas" otorgado por The American Fundation en New York, el 25 de 
octubre de 1989 y que reprodujo en su obra "Con América nace la Nueva Historia", expresó: "América representa la más intensa vivencia del Hombre en busca de una sociedad nueva de integración universal. Con ella surge la esperanza de una vida más justa”. ${ }^{29}$

Para América, Tomás Moro inventó la palabra "utopia". Bolívar decía que la Libertad de América es la esperanza del universo. América es tierra de emancipaciones: se emanciparon los europeos. Sus hijos, los criollos, culminaron la Guerra de Independencia y se emanciparon los negros de sus amos negreros de las haciendas: por ello, América es la Tierra de la Libertad.

La lucha contra la opresión en América Latina y a favor de la Libertad siempre la señaló con insistencia en su pluma combativa, el Maestro Arciniegas. En su obra "Los Pinos Nuevos" que publicó en Tunja en el Instituto de Estudios para la Integración de América Latina (IDESIL) en 1982, se enfrentó contra las nuevas dictaduras de la izquierda, entre ellas Cuba, la tierra de sus ancestros maternos y, de todos los tipos de represión contra la democracia representativa. Es la idea de libertad de un humanista americano que se preocupó ante la situación de Cuba, Haití, el Caribe, los países centroamericanos y los regímenes militares de diversos países latinoamericanos. Si la ideología del Demoliberalismo con la cual se organizaron en el siglo XIX los Estados Nacionales de América Latina, está en crisis, la solución no es la represión y el terrorismo, o la adopción de nuevos modelos europeos y asiáticos con estructura hacia la socialización, sino el fortalecimiento de la libertad, la democracia, la justicia social, la igualdad y la justa distribución de los bienes en naciones libres, iguales y con derechos individuales.

\section{La Educación y la identidad cultural de América Latina}

El Maestro Germán Arciniegas se preocupó por reflexionar sobre la educación y la identidad cultural de Latinoamérica, teniendo en cuenta que la formación de las nuevas generaciones es fundamental para la dirección del futuro de Nuestra América. La EDUCACIÓN significa la suma total de procesos por medio de los cuales una comunidad transmite su creatividad cultural, usos y técnicas a las jóvenes generaciones con la Educación. Por ello es necesario que los latinoamericanos se preocupen por formar a las nuevas generaciones, pensando en la identidad de la cultura latinoamericana, pues los hechos educativos y culturales llevan a la formación de las jóvenes generaciones a través del tiempo. 

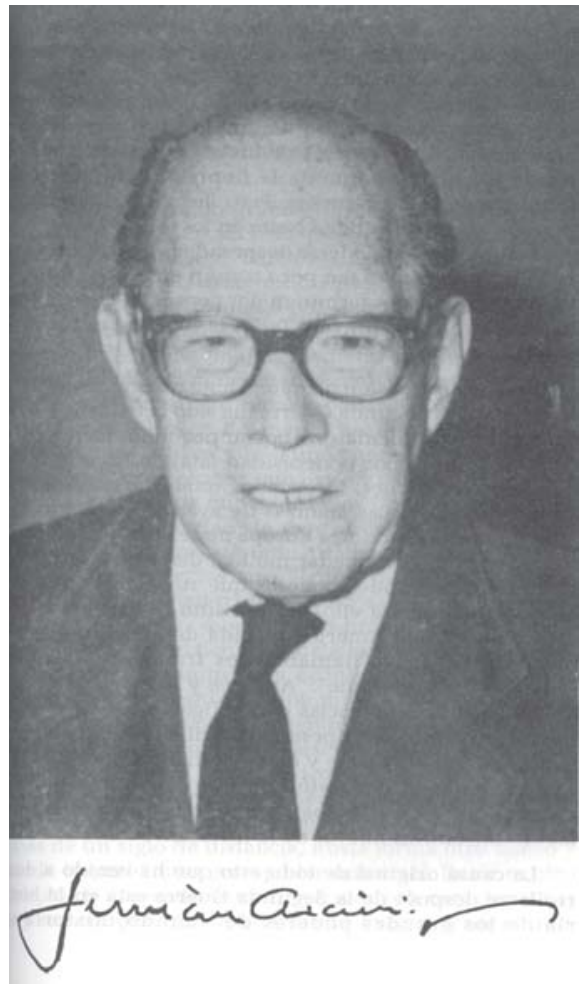

El Maestro Germán Arciniegas en su posición de Ministro de Educación en los Gobiernos de los Presidentes Eduardo Santos y Alberto Lleras Camargo, en su primera administración, se interesó por la formación de los "Maestros de Maestros" en la Escuela Normal Superior de Colombia y por el fomento de la investigación científica de las Ciencias Humanas, que llevó a la fundación del Instituto Caro y Cuervo para la investigación filológica y el Instituto Etnológico Nacional para la investigación antropológica y arqueológica. En la misma forma se interesó por el fomento de la investigación histórica, literaria y en general de las Ciencias Sociales.

Con la educación universitaria, el Ministro Arciniegas se interesó por el fomento y adelanto en la educación primaria y secundaria; la organización y consolidación de las Escuelas Normales, tanto masculinas como femeninas, las Escuelas Normales Rurales y una nueva visión de la Educación. Con su influencia las mujeres ingresaron a las Universidades colombianas. En la misma forma, se interesó por la edición de obras a bajos precios, la Biblioteca Popular, para facilitar la lectura a los educandos y a las gentes en general.

Un gran interés del Maestro Arciniegas fue la educación de las juventudes colombianas, con una filosofía de identidad y autenticidad latinoamericana. En el análisis de la identidad latinoamericana, el Maestro Arciniegas señaló que en el transcurso de dos siglos después de la Revolución de Independencia, se manifestó en los latinoamericanos una confrontación entre las dos grandes tendencias histórico-culturales. Por una parte, la búsqueda de una identidadpropia y auténtica de América Latina, la cual representa la síntesis cultural, con los aportes indígenas, españoles y africanos, con un modelo que debe surgir de la misma realidad. Y por otra, la tendencia que busca la imitación del modelo externo, como única garantía para alcanzar el progreso y el bienestar de los latinoamericanos. Una imitación de las ideologías, constituciones e instituciones políticas, económicas, sociales, culturales y educativas, que han tenido éxito en Europa y/o Estados Unidos, y consideradas como patrimonio universal para todos los pueblos. ${ }^{30}$ 
Estas dos tendencias: el eurocentrismo de carácter universalista y el nacimiento cultural, se reflejan en la literatura, la educación, el arte, la historiografía, la antropología y en todas aquellas manifestaciones de la creación espiritual y material de los latinoamericanos. El universalismo cultural se proyectó en algunas corrientes culturales como el neoclasicismo, el modernismo y el vanguardismo. Y por su parte, el nacionalismo cultural hispanoamericano se proyectó en corrientes culturales como el romanticismo, el costumbrismo, el indigenismo, el nativismo y otros movimientos de afirmación de la identidad nacional.

Con el problema de la identidad cultural, encontramos otra tendencia en Latinoamérica que se relaciona con la lucha por su "independencia”, entendida como “libertad”. Desde finales del siglo XVIII se proyectó el anhelo de los latinoamericanos por la liberación de la dominación colonial y la obtención de la libertad, la cual debe llevar a la autodeterminación.

La idea de la independencia a través de la revolución se presenta para los latinoamericanos como la panacea para realizar los cambios urgentes que requiere la sociedad y como una evasión de todos los problemas de su realidad presente. Esto señala que la lucha por la independencia es constante desde la segunda mitad del siglo XVIII, cuando por primera vez se pensó en la independencia cultural americana en relación con la dependencia cultural europea.

Otro problema de reflexión que hizo el Maestro Arciniegas en el desarrollo cultural de Latinoamérica es la tendencia regional que proyecta movimientos culturales autóctonos de acuerdo con los caracteres regionales. Latinoamérica se presenta como un continente de regiones sociales con diversos sistemas de vigencias parciales, usos, costumbres y tradiciones; presenta en su esencia una estructura regional. Algunas tendencias culturales se manifiestan en las regiones, de acuerdo con su conformación étnica y cultural. Algunos ejemplos los encontramos en los movimientos de indigenismo y negritud.

Una preocupación que encontramos en la obra del Maestro Germán Arciniegas es el vacío de identidad latinoamericana y la falta de una conciencia cultural que se convierta en una infraestructura que posibilite su integración en lo político, económico y social. Es por ello que Arciniegas plantea un tipo de Integración Cultural de América Latina, la cual debe partir de la EDUCACIÓN y en la formación de las nuevas generaciones que se preparan para afrontar la dirección de la sociedad en el siglo XXI. Se considera importante que los latinoamericanos conozcan su cultura y sus propios valores y se identifiquen con "lo propio" ante las demás culturas del mundo; que aprendan a valorar su originalidad, a aprovechar los logros de la cultura universal, y a alejar "la imitación" sin ningún esfuerzo de creatividad. 
El Maestro Germán Arciniegas consideró fundamental que los latinoamericanos conozcan esas fuerzas internas de coherencia y unidad cultural, las cuales están alrededor de sus caracteres, creencias, costumbres, tradiciones, su esencia y su espíritu colectivo. Alrededor de sus obras, consideramos los esfuerzos del Maestro para el fortalecimiento de la integración culturalparticipante que penetre en el pueblo latinoamericano a través de la educación y la creación cultural, y esté ligada a la justicia social, el progreso económico, el adelanto cultural y la lucha por la libertad contra el despotismo y el autoritarismo, tanto de la derecha como de la izquierda. Precisamente lo que podemos sintetizar en el pensamiento y acción del Maestro Germán Arciniegas: "un americanismo en la libertad".

\section{El Maestro Germán Arciniegas y la Filosofía de la Historia Americana}

Un aspecto muy importante en la obra del Maestro Arciniegas es su interpretación constante de la Historia del Nuevo Mundo. Es el sociólogo y el ensayista de la historiografía americana y por esencia, un filósofo de la Historia Latinoamericana. El filósofo de la Historia a través del ensayo, es un hermeneuta o intérprete de los hechos históricos en el espacio y en el tiempo; es el que reflexiona con la etiología de las ideas en la síntesis histórica, teniendo en cuenta la Unidad del Devenir que une el presente con el pasado y las líneas tendenciales hacia el futuro.

El Maestro Germán Arciniegas, a través de sus ensayos interpretativos sobre Nuestra América, reflexionó sobre su presente, apoyado en el proceso histórico que viene desde el "Encuentro de Culturas" en el continente americano desde hace 500 años. En la misma forma, interpretó en prospectiva, el futuro del Nuevo Mundo, por medio de la comprensión del momento actual. En sus obras "El Continente de Siete Colores" (Historia de la Cultura en América Latina), "Estepueblo de América", "América tierra firme", "América mágica", "América en Europa", "Con América nace la nueva Historia", "Galileo mira a América", "Entre la Libertady elMiedo", "Biografía del Caribe", "Nueva imagen del Caribe", "El revés de la Historia” y otras, el Maestro Arciniegas se manifestó como el ensayista, el sociólogo y el filósofo de la Historia de América Latina. Siempre estuvo actualizando y relacionando el Historia del presente latinoamericano al pasado. Fue el filósofo de la Historia del Nuevo Mundo, cuya hermenéutica de los hechos históricos lo llevaron a la comprensión de los conjuntos históricos, y en especial, en su reflexión sobre la Historia de 
América en los cinco siglos del Encuentro de Culturas, en el panorama histórico de las Civilizaciones en el mundo moderno y contemporáneo.

El filósofo de la Historia y ensayista es cíclico en cuanto siempre relaciona la Unidad del Devenir, uniendo los caminos que conducen a la Historia, pues ella está en la entraña de todo conocer o hacer. Es la visión de la Historia como el transcurrir de la Sociedad en el tiempo. No se preocupa solamente por el Hombre en el pasado, sino por esa Unidad del Devenir que une el pasado de América Latina con el presente y con líneas tendenciales hacia el futuro. Esa América mágica, ese continente de siete colores, esa tierra de la Libertad y la Democracia, debe ser interpretada en el proceso de cinco siglos para medir sus tendencias históricas, sus rasgos y caracteres más significativos y su presencia grande en la Historia Universal.

En su trabajo intelectual, el Maestro utilizó dos métodos en el estudio, análisis e interpretación: el deductivo general y el inductivo particular. Siguiendo el método deductivo, que nos legó Platón, el filósofo griego, Arciniegas interpretó en conjunto el proceso histórico de América y su presencia y aporte en la dinámica de las civilizaciones en la Historia Universal. Según sus ideas que refleja en su estudio "500 años de América y de Europa",

El 12 de octubre de 1492, un marino genovés comunicó los dos bemisferios en una operación mágica. Venían flotando en el infinito Arcano. Eran dos medias naranjas sueltas desde que la Historia existe. La tierra estaba partida en esas dos mitades que se ignoraban en forma absoluta. Colón las junta y desde ese día la Historia se hace universal. Europa era chiquita. Terminaba poco más allá del Estrecho de Gibraltar. Desde que América aparece, el mundo entero cambia. Durante tres siglos cayeron los imperios indígenas de Moctezuma y Atabualpa; pero también en la Revolución de Independencia cayeron los imperios de España, Portugal, Inglaterra y Francia. ${ }^{31}$

El método inductivo, siguiendo los planteamientos de Aristóteles, que analizó el Maestro Germán Arciniegas en sus ensayos, es muy significativo, pues parte de hechos particulares, crónicas, narraciones y hechos menores e insignificantes de "la pequeña historia", a través de los cuales lleva la interpretación histórica de lo individual a lo general, de lo acontecimental microhistórico a lo universal, utilizando una lógica histórica con revelaciones de gran alcance. De los más mínimos detalles y de cosas rutinarias, encauza la interpretación a lo grandioso. La alimentación de la papa y el maíz, 
frutos americanos, con cambios sustanciales en la comida europea; la pimienta, la canela y en general las especias, con influencia decisiva en el Descubrimiento de América.

Los europeos que buscaban las especias en Asia y la India, encontraron en América nuestros productos que revolucionaron la comida europea: la turma que después fue llamada papa, el maíz, el cacao, el tabaco, el tomate y muchos otros. Inicialmente el maíz sirvió para alimentar cerdos y como comida para los más pobres; la papa fue prohibida, pues se consideró que producía lepra, y el tabaco o "yerba de Nicot", solamente se vendía con fórmula médica. Después de varios siglos, la turma que se convirtió en bocado de "Sumo Pontífice" o "papa", se generalizó en Europa y hasta se convirtió en el vodka de los rusos. Asimismo, el maíz y los tomates, el tabaco se convirtió en elemento esencial en las Cortes europeas. Se generalizaron las colecciones de tabaqueras y cigarrilleras, de oro, plata, marfil, ébano, adornadas con perlas y rubíes. ${ }^{32}$

Con su método inductivo resucita crónicas, narraciones y hechos pasados y los lleva hasta el presente con gran agilidad. Les imprime grandiosidad, utilizando una prosa que es de gran perfección en el estilo, muy ágil, sencilla y a la vez hermosa con finura en su lirismo. Le interesa transmitir mucha claridad en su pensamiento y transparencia en las imágenes. Es un artista en su prosa del ensayo histórico, sin muchos adjetivos, ni verbalismos exagerados, ni retórica vana. Sus críticos literarios, que son muchos, según la obra compilada por el escritor Juan Gustavo Cobo Borda y que llama "Una visión de América. La obra de Germán Arciniegas desde la perspectiva de sus contemporáneos". Uno de ellos, Salvador Pineda en su estudio "Presencia de Germán Arciniegas" nos señala lo siguiente:

es un maestro de la expresión; es un maestro del ideal práctico. Posee el verdadero secreto de la pedagogía: la sugerencia. Quien lo lee o escucha, encuentra de inmediato motivos propicios para ampliar y profundizar pensamientos propios. Ninguno tan incitante y atractivo en la lectura como el escritor colombiano que juega literariamente con la Historia: guia al lector con mano suave por los caminos del tiempo para dejarlo después, como encaminador de almas, seguir por su propia cuenta

32 ARCINIEGAS, Germán. (1975): América en Europa, Buenos Aires, Editorial Sudamericana. 
en busca de nuevos derroteros. Es un buen historiador minucioso y exigente; pero más que simple narrador cronista, es un sociólogo de la Historia o mejor, una historia sociológica de la vida. ${ }^{33}$

El ensayista Arciniegas describe para su época y desde su época en el mundo contemporáneo del siglo XX. Por ello, los temas de su mayor interés están subordinados a las circunstancias del presente vivido. En la Década de los Cincuenta vivió en Europa y en los Estados Unidos. Viajó por todos los países latinoamericanos, recalcando siempre la idea de fortalecer la Libertad y la Democracia contra todo tipo de Despotismos y Dictaduras. En cada país de su viaje por América Latina escribía en los periódicos y en las revistas, señalando los problemas de las Dictaduras y la necesidad de la Democracia y la Libertad. En la misma forma, destacaba para cada país sus propios valores, creatividad y aportes a la cultura latinoamericana y universal. ${ }^{34}$

En su obra "Entre la Libertady el Miedo" atacó a los caudillos y tiranuelos de América Latina. Este libro fue rigurosamente prohibido en los regímenes dictatoriales que torturaron a América Latina. El Maestro Arciniegas se convirtió en la figura más representativa de la oposición moral a los regímenes dictatoriales que torturaron a América Latina. Así como el cubano José Martí en el siglo XIX, Arciniegas se refugió en Nueva York en las Décadas de los Cuarenta y Cincuenta. Fue una oposición activa contra las Dictaduras. Los tiranuelos tuvieron pánico a sus escritos, en los cuales señaló que América Latina vive entre la Libertad y el Miedo, entre la Democracia y la Dictadura. Por todos lados luchó por la Libertad y la Democracia con justicia social. Una América libre, interdependiente y democrática, asentada sobre una base amplia de justicia social, será el motor de la Historia universal. ${ }^{35}$

Para el ensayista Arciniegas, lo más importante es la interpretación; por ello se considera que es un hermeneuta o etiólogo del Devenir histórico latinoamericano; asimismo, un especialista de la interpretación sobre América Latina. El valor del ensayo histórico no depende del número de documentos o de la infinidad de datos históricos, sino del poder de las intuiciones que se vislumbran y de las sugerencias capaces de despertar en el lector.

\footnotetext{
${ }^{33}$ COBO BORDA, Juan Gustavo. (1990): Una visión de América. La obra de Germán Arciniegas desde la perspectiva de sus contemporáneos, Bogotá, Instituto Caro y Cuervo, Granada entreabierta.

${ }^{34}$ CACÚA PRADA, Antonio. (1990): Germán Arciniegas. Su vida contada por él mismo, Bogotá, Instituto Colombiano de Estudios Latinoamericanos y del Caribe, Universidad Central.

${ }^{35}$ ARCINIEGAS, Germán. (1952): Entre la Libertad y el Miedo, México, Editorial Cultura.
} 
El filósofo de la historia a través del ensayo, como lo hizo el Maestro Germán Arciniegas, llega a la Hermenéutica para buscar el sentido y la comprensión de los hechos históricos; para nuestro ensayista Arciniegas, la explicación histórica de América en su proceso civilizatorio. Es la síntesis histórica y la filosofía de la Unidad del Devenir, a través de la cual, el ensayista busca las unidades y las diversidades, la correlación de los hechos, los aspectos generales y particulares, las fuerzas históricas y los factores condicionantes. Y el conocimiento histórico, producto de la investigación, que llega por último a la comprensión histórica.

La mayor tendencia en los ensayistas filósofos de la Historia en el mundo actual, como el Maestro Germán Arciniegas, es la recreación del pasado humano para comprender el presente, y la búsqueda de las esencias históricas, mediante la intuición esencial. Tenemos en cuenta que el conocimiento aprehende por abstracción el fondo esencial de las cosas. ${ }^{36}$

\section{El Papel de los Individuos y las Masas en la Historia de América}

Un gran tema de interpretación histórico-cultural que insistió el Maestro Arciniegas en sus estudios históricos fue el Papel de los Individuos y las Masas en la Historia de América. En sus obras reflexiona sobre esa fuerza mágica que tienen los superhombres o héroes y las masas populares en los cambios de la Historia.

Según sus ideas, en la Historia de la Humanidad surgen aquellas personalidades: individuos creadores, héroes, videntes, místicos, líderes y grandes caudillos, que se preocupan por la creatividad y por el espíritu mágico de una dirección de la sociedad hacia una meta o utopía, de lo que se cree que es la plenitud de la felicidad, el bienestar y el progreso de los pueblos. Ellos son "la levadura de la Historia", la que los impulsa a la creatividad y al quijotismo.

Los creadores, los carismáticos, los grandes líderes actúan sobre las masas por sugestión, inspirándolas y llevándolas a actuar en cohesión social, y con una meta común. En esa acción dinámica se percibe una fuerza mágica de los super-hombres como José Antonio Galán, el caudillo de los Comuneros, o Simón Bolívar, el Libertador; y una fuerza mágica de las 
masas populares, como las Comuneras del Socorro y las masas en la revolución política de 1810 y en la Guerra de Independencia. Es la fuerza mágica del pueblo soberano - opina el Maestro Arciniegas en su obra "América mágica".

Según "El Hombre de las Américas", en la Historia Americana se manifiestan las dos interpretaciones opuestas: La individualista y la colectivista. Para el Maestro, los Agentes históricos no son únicamente los individuos creadores disociados o abstraídos de las masas, ni viceversa. Esos individuos superhombres o héroes y esas masas populares son creadoras y mágicas y llevan al cambio en la Historia.

En "América mágica" el Maestro Arciniegas se preocupa por el sentido mágico de América a través de sus héroes, poetas o santos. Juárez en México, Sarmiento en Argentina, José Martí en Cuba, José Artigas en Uruguay, Juan Montalvo en Ecuador y el peruano Manuel González Prada. Ellos se sumergieron en su realidad histórica y con su fuerza mágica y carismática edificaron el futuro de sus países. Juárez fue el silencioso edificador del futuro de México; Sarmiento, quien reflexionó sobre Argentina y señaló rumbos hacia el futuro de este pueblo de Sudamérica. ${ }^{37}$

En "América mágica" también aparecen ilustres figuras como Fray Servando Teresa de Mier, Esteban Echeverría, Santa Rosa de Lima, Cuauthémoc y José Martí, con la excelencia de una aureola americana. Y en lo mágico de América aparece la figura de BOLÍVAR, el héroe contradictorio, forjador de la Libertad de América y víctima de su propia victoria; él es el espejo de la época, según Arciniegas. Si Andrés Bello, ingeniero de repúblicas era monárquico, Bolívar sembrador de libertades era, al mismo tiempo, enemigo de la democracia.

Los grandes hombres de América que transmitieron una fuerza histórica dinámica a sus pueblos, los presenta el Maestro Arciniegas como "ejemplos" o modelos de la grandeza humana americana. Heroísmo, virtud, poder mágico, hazaña y trascendencia histórica. Ellos representan lo mágico de América y su interés por crear la cultura propia de cada país. Ese pensamiento de identidad que refleja en América lo que es argentino, mexicano, chileno o colombiano.

Según el Maestro Arciniegas, América Latina ha pasado por dos coyunturas históricas: la época de la conquista y colonización en el siglo XVI y la coyuntura de la Independencia en el siglo XIX. Alrededor de 
estas coyunturas hay grandes líderes y continuadores que siguen sus planteamientos o los distorsionan. De hecho, los grandes líderes como Hernán Cortés, Francisco Pizarro, Pedro de Alvarado, Gonzalo Jiménez de Quesada y Pedro de Valdivia en el siglo XVI; y los grandes Libertadores de América: Bolívar, San Martín, Bernardo O’Higgins, José Artigas, Miguel Hidalgo, José María Morelos y otros, tienen sus caudillos y gamonales, continuadores y distorsionantes de los grandes propósitos. Entre ellos mencionamos a los dictadores Rosas, García Moreno, Porfirio Díaz, Cipriano Castro, Juan Vicente Gómez, José Domingo Perón y otros.

En sus estudios sobre la participación de los sectores populares en las rebeliones, sublevaciones, motines y revoluciones en América Latina, interesaron a los revisionistas históricos de la primera mitad del siglo XX. Desde el siglo XVIII se manifestaron los movimientos de masas del mundo rural campesino, llanero, montoneras, indios, mestizos y negros; las rebeliones de las gentes del común de los de abajo; el pueblo anónimo que con sus caudillos populares, se convirtieron en las fuerzas históricas que llevaron a los grandes cambios históricos en Nuestra América. Es el interés por hacer la Historia desde lo colectivo, desde la intrahistoria, la íntima historia del hombre del común.

El maestro Germán Arciniegas en sus obras "Los Comuneros”, "20.000 Comuneros hacia Santafe", "Este Pueblo de América", "El revés de la Historia", "Bolivary la Revolución”, "Cosas del Pueblo", "Crónicas de Historia Vulgar" y en otros ensayos, señala el papel del pueblo en la Historia de América. Los movimientos de masas en los Comuneros del Socorro y de Túpac Amarú en el Perú; la participación en la Guerra de Independencia americana y en las guerras civiles del siglo XIX, señalan que el pueblo siempre está presente en las grandes hazañas de la epopeya americana. Es la esencia de Nuestra América, que según el Maestro Arciniegas, no es latina, sino ladina o Mestiza. ${ }^{38}$

El Maestro Arciniegas opina que es muy significativo y cambiante, hacer una Historia de América vista desde abajo. Invertir los términos en la manera de escribir la Historia, pues los pueblos siempre están presentes en ella. Cuando la Historia se mira desde abajo, y se humaniza, el mundo se ve más ancho y se hace más comprensible que desde el alocado mirador de las biografías. Lo que pierde en colores, lo gana en emoción humana.

${ }^{38}$ ARCINIEGAS, Germán. (1993): América Latina, México, Fondo de Cultura Económica. 
En sus estudios históricos, se interesa por las fuerzas históricas populares, en las cuales los héroes son "las gentes del común”. Su interés por lo popular más importante que por la historia militar de los héroes y próceres apergaminados y con charreteras. Cuando estudian los líderes populares Túpac Amarú y Galán, los relaciona muy directamente con las masas comuneras del Perú y de la Nueva Granada, que los impulsaron a la acción.

En la relación entre las masas populares y los líderes carismáticos, el Maestro Arciniegas encuentra una fuerza mágica del pueblo soberano, que se relaciona con la fuerza mágica de los superhombres. Es la muchedumbre anónima de aldeanos y rústicos comuneros que se rebela contra las leyes que aumentan los impuestos y contra la situación social. El Maestro Arciniegas combina su visión de la historia con las dos interpretaciones opuestas: la individualista de los líderes y caudillos carismáticos, y la colectivista de las masas comuneras contra el orden económico y social. Para él, los agentes históricos no son únicamente los individuos creadores, disociados o abstraídos de las masas populares, ni viceversa. Esas masas son creadoras y mágicas que llevan el cambio en la Historia. Esta interpretación histórica de América Latina, lleva al Maestro a una visión sociológica y filosófica del acontecer americano y de las fuerzas internas que se mueven durante varios siglos, las cuales se perciben en tiempos de coyuntura o de larga duración.

En su obra histórica "Los Comuneros", escrita en 1938 en forma novelada, descriptiva, con relatos históricos basados en fuentes primarias documentales, con narraciones, descripciones de paisajes, costumbres, aspectos sugestivos de la pequeña historia, y el acaecer diario de la vida cotidiana, interpreta la Historia Social de América, desde el enfoque popular americano. Interpreta el hecho histórico del Nuevo Reino de Granada de 1781, en relación con los movimientos populares del siglo XVIII, que buscaron las reivindicaciones socio-económicas, que también ocurrieron en Paraguay, Perú, México, Cuba, Venezuela, Brasil y de otras regiones de América. El Maestro Arciniegas analiza la participación de las masas, que en años posteriores fueron decisivas en la culminación de la Guerra de Independencia americana. El papel de los individuos y las masas en la Historia es el aporte más significativo del Maestro Arciniegas para el conocimiento de las fuerzas profundas sociales en la Historia de América. ${ }^{39}$

${ }^{39}$ ARCINIEGAS, Germán. (1980): Los Comuneros, Bogotá, Pluma. 
Para los colombianos y latinoamericanos, el Maestro Germán Arciniegas es uno de los grandes ensayistas y filósofos de la Historia de América. Es el creador de una conciencia americana, a través de sus obras y de sus numerosos ensayos que llevan en su esencia la pasión por presentar a América, el NUEVO MUNDO en el proceso histórico de las civilizaciones. A través de sus obras busca las esencias de los hechos de los pueblos americanos a través del tiempo y en este espacio continental. Con intuición histórico-filosófica llegó a la comprensión histórica de América, a través de la correlación, comparación, construcción histórica y síntesis. La interpretación lo llevó a la etiología de las ideas y a la filosofía de la Historia americana. el Maestro tuvo pasión por el Nuevo Mundo o América en su totalidad: América frente a Europa y en el proceso histórico de las civilizaciones.

\section{CONCLUSIONES}

El Maestro Germán Arciniegas es el escritor colombiano que en sus obras y artículos más reflexionó sobre América Latina, que se convirtió en pasión humanística constante y en el motivo central de su vida intelectual. En su cátedra de América que fue constante en sus actividades universitarias; en sus permanentes escritos periodísticos y en sus numerosas obras y artículos que publicó en diversas revistas y periódicos, se manifestó como el culturólogo e intérprete del Devenir histórico de este pueblo de la libertad, la independencia, la democracia y la república.

El Maestro Arciniegas siempre se preocupó por el sentido de lo americano; por la búsqueda de la ontología o razón de ser de Nuestra América; por la búsqueda de la identidad de Latinoamérica; su esencia y su presencia ante el mundo; sus contribuciones a la Cultura Universal; su posición en la Historia de la Humanidad, y lo que ha sido en los 500 años del Encuentro de Culturas. América es la tierra de la democracia, la libertad y la República, que son los aportes más significativos del Nuevo Mundo a la Historia de las Civilizaciones.

En el discurrir de su vida, luchó contra las dictaduras, los despotismos y las tiranías que llenaron el vacío político del poder democrático en América Latina. Por ello, fue el intelectual que más se enfrentó a los dictadores y tiranuelos que pulularon en Nuestra América, quienes lo persiguieron y prohibieron sus obras, declaradas subversivas. Son ejemplos sus escritos y luchas contra los dictadores del Caribe, como bien lo expresaron sus obras "Entre la Libertad y el Miedo", "Biografía del Caribe", "Este pueblo de América”y otras. Por ello, siempre señaló que Latinoamérica debe luchar por la libertad, 
pues ella fue el ideal de los Libertadores. Sin embargo defendió la idea de que la Libertad y la Democracia en plenitud no son posibles sin la Justicia social. Ello indica que Libertad y Justicia social deben ser inseparables. Una América libre, independiente, democrática, asentada sobre una base amplia de Justicia social, sería un motor en la Historia.

Un aspecto muy significativo en sus obras, son sus investigaciones sobre la picaresca americana, "la pequeña historia" y la vida cotidiana en Nuestra América Mestiza. Son muy graciosas y amenas para leer sus múltiples anécdotas y biografías de numerosos personajes, con los cuales lleva a la esencia de los fenómenos históricos. Es el eximio pensador de América Latina; el piloto mayor en la tarea de redescubrir el continente. Su pensamiento ha sido la interpretación más original que se ha hecho sobre el Nuevo Mundo. Lo anterior afirma la grandeza intelectual del Maestro Germán Arciniegas, "El Hombre de las Américas", "El Caballero de la Libertad" y el "Colombiano universal". El Maestro nos legó el amor por la cultura latinoamericana, la nuestra, con los grandes valores y atributos, y con un puesto muy significativo en el proceso histórico de las Culturas y Civilizaciones en el panorama universal.

\section{FUENTES}

\section{OBRAS DEL MAESTRO ARCINIEGAS}

- ARCINIEGAS, Germán. (1932): La Universidad Colombiana. Bogotá, Imprenta Nacional.

(1939): Jiménez de Quesada, Bogotá, Editorial ABC.

(1941): Los Alemanes en la Conquista de América, Buenos

Aires, Editorial Losada.

(1955): Amérigo y el Nuevo Mundo, Bogotá, Editorial

Hermes.

Editorial Sudamericana.

Suramericana.

(1962): El mundo de la bella Simonetta, Buenos Aires, Editorial

(1974): Estepueblo de América, México, Secretaría de Educación.

(1978): El caballero de El Dorado, México, Aguilar, 1978.

(1980): El revés de la Historia, Bogotá, Plaza \& Janés.

(1980): Los Comuneros, Bogotá, Pluma, 1980

(1981): 20.000 comuneros hacia Santa Fe, Bogotá, Editorial

Pluma.

(1982): América tierra firme, Bogotá, Plaza \& Janés.

(1982): El estudiante de la Mesa Redonda, Bogotá, Plaza \& Janés. 
(1982): Los Pinos nuevos. Diario de un sonámbulo enamorado,

Tunja, Editorial Bolivariana Internacional, IDESIL.

(1984): Bolivary la Revolución, Bogotá, Planeta.

(1986): América mágica. Las mujeres y las horas, Santiago de

Chile, Editorial Andrés Bello.

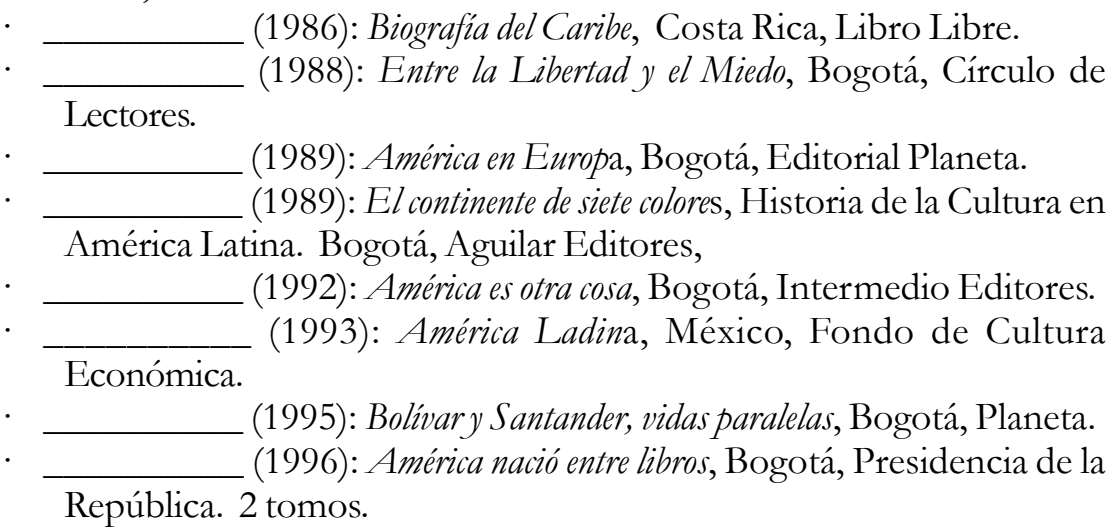

\section{SELECCIÓN BIBLIOGRÁFICA}

ACADEMIA COLOMBIANA DE HISTORIA. (1929): Causas célebres a los precursores, Bogotá, Academia Colombiana de Historia.

ALAMEDA OSPINA Raúl. (2005): Los Movimientos estudiantiles y el movimiento político en Colombia, en Movimientos Universitarios. América Latina Siglo XX, VARGAS, Olmedo Tunja, Rudecolombia.

ARÉVALO, Juan José. (1956): Fábula del tiburóny las sardinas, América Latina estrangulada. México, Ediciones América Nueva.

BOLETÍN DE HISTORIA Y ANTIGÜEDADES, DE LA ACADEMIA COLOMBIANA DE HISTORIA, (2000) Homenaje al Maestro Germán Arciniegas, Bogotá, Academia Colombiana de Historia.

CACÚA PRADA, Antonio. (1990): De Cuba a Boyacápor la Libertad. Dos Angueyras y Germán Arciniegas, Tunja, Biblioteca de la Academia Boyacense de Historia. - (1990): Germán Arciniegas. Su vida contada por él mismo. Bogotá, Universidad Central, ICELAC.

COBO BORDA, Juan Gustavo. (1987): Arciniegas de cuerpo entero. Bogotá, Planeta. , (Compilador). (1990): Una visión de América. La obra de Germán Arciniegas desde la perspectiva de sus contemporáneos, Bogotá, Instituto Caro y Cuervo, Granada entreabierta. 
. (1990): Cronología y Bibliografía, Bogotá, Ed. Planeta.

CÓRDOBA, Federico. (1950): Vida y obra de Germán Arciniegas, Habana, Ministerio de Educación, Dirección de Cultura.

COLLINGWOOD, R.G., "Idea de la Historia". México, Fondo de Cultura Económica, 1965

EMBAJADA DE ESPAÑA,/ FUNDACIÓN SANTILLANA. (1995): Arciniegas y España, Santafé de Bogotá.

ESQUENAZI MAYO, Roberto. (1997): Experiencias de toda una vida: Cartas de Germán Ariniegas, USA, Universidad de Colorado, Departamento de Español.

FUNDACIÓN SANTILLANA. (1990): Arciniegas corresponsal del mundo. 19281989, Bogotá, Fundación Santillana.

LAURENCE, Bandin, (1996): El Análisis de Contenido, Madrid, Ediciones Akal.

NARANJO VILLEGAS, Abel. (1965): Morfología de la Nación Colombiana (Aproximación a su Antropología Cultural), Bogotá, Academia Colombiana de Historia, Historia Extensa de Colombia, Tomo XXII. Ediciones Lerner.

OCAMPO LÓPEZ, Javier. (1978): Educación, Humanismo y Ciencia, Tunja, Universidad Pedagógica y Tecnológica de Colombia.

- (1981): Historia Ideas de Integración de América Latina. Tunja, Editorial Bolivariana Internacional, págs. 267-287.

PUYANA MUTIS Aura María. (2004): Vigencia y caducidad del Movimiento de Córdoba. 1918-1919, en Movimientos Universitarios. América Latina Siglo XX,: VARGAS Olmedo, Tunja, Rudecolombia.

VERA DE FLACHS, María Cristina. (2005): Reformas y contrarreformas, en: la Universidad de Córdoba 1918-1936, en Movimientos Universitarios. América Latina Siglo XX, VARGAS Olmedo, Tunja, Rudecolombia.

VOVELLE, Michel. (1985): Ideologías y mentalidades, Barcelona, Editorial Ariel.

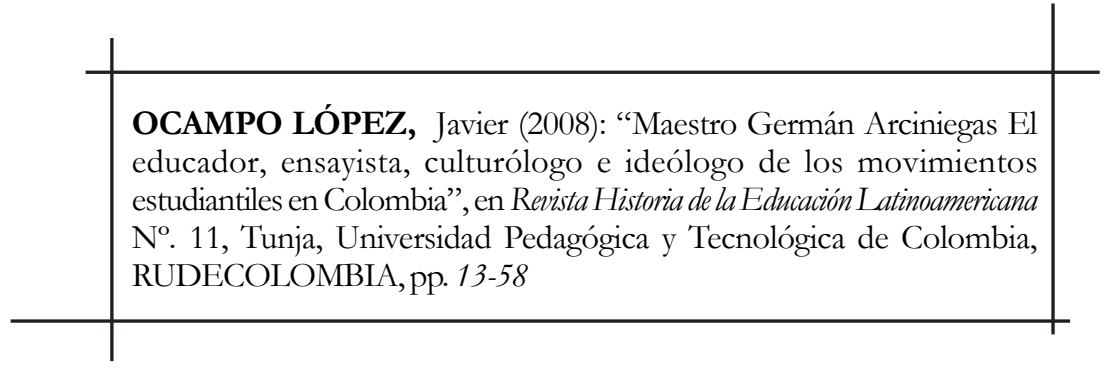

